\title{
Changes in zooplankton community, and seston and zooplankton fatty acid profiles at the freshwater/saltwater interface of the Chowan River, NC
}

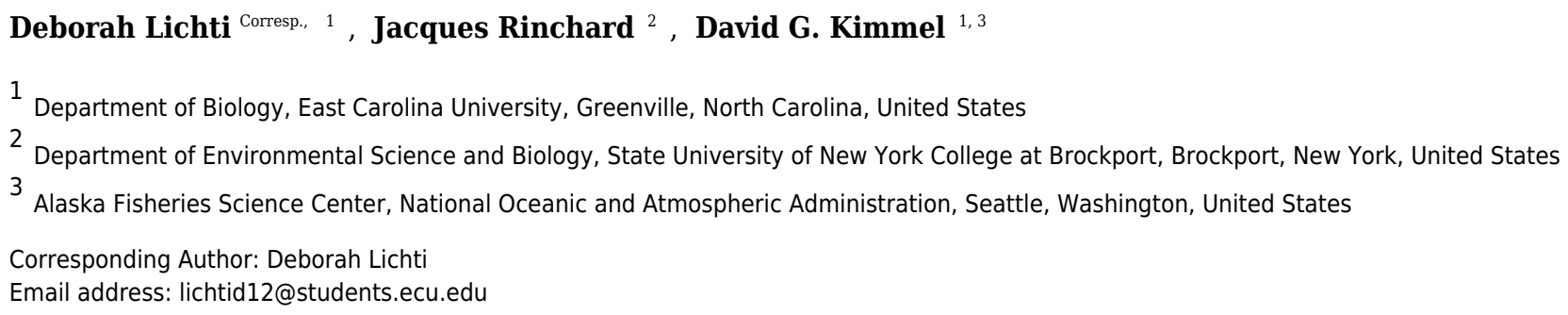

The variability in zooplankton fatty acid composition may be an indicator of larval fish habitat quality as fatty acids are linked to fish larval growth and survival. We sampled an anadromous fish nursery, the Chowan River, during spring of 2013 in order to determine how the seston fatty acid composition varied in comparison with the zooplankton community composition and fatty acid composition during the period of anadromous larval fish residency. The seston fatty acid profiles showed no distinct pattern in relation to sampling time or location. The mesozooplankton community composition varied spatially and the fatty acid profiles were typical of freshwater species in April. The Chowan River experienced a saltwater intrusion event during May, which resulted in brackish water species dominating the zooplankton community and the fatty acid profile showed an increase in polyunsaturated fatty acids (PUFA), in particular eicosapentaenoic acid (EPA) and docosahexaenoic acid (DHA). The saltwater intrusion event was followed by an influx of freshwater due to high precipitation levels in June. The zooplankton community composition once again became dominated by freshwater species and the fatty acid profiles shifted to reflect this change; however, EPA levels remained high, particularly in the lower river. We found correlations between the seston, microzooplankton and mesozooplankton fatty acid compositions. Salinity was the main factor correlated to the observed pattern in species composition, and fatty acid changes in the mesozooplankton. These data suggest that anadromous fish nursery habitat likely experiences considerable spatial variability in fatty acid profiles of zooplankton prey and that are correlated to seston community composition and hydrodynamic changes. Our results also suggest that sufficient prey density as well as a diverse fatty acid composition is present in the Chowan River to support larval fish production. 
1 Changes in zooplankton community, and seston and zooplankton fatty acid profiles at the

3

Deborah A. Lichti ${ }^{*}$, Jacques Rinchard ${ }^{2}$, and David G. Kimmel ${ }^{1,3}$

${ }^{1}$ Department of Biology, East Carolina University, N108 Howell Science Complex, Greenville, NC, 27858, USA

${ }^{2}$ Department of Environmental Science and Biology, College of Brockport- SUNY 350 New Campus Drive, Brockport, NY 14420, USA

${ }^{3}$ Present Address: NOAA Alaska Fisheries Science Center, 7600 Sand Point Way NE, Seattle, WA 98115 , USA 


\section{Abstract}

32

The variability in zooplankton fatty acid composition may be an indicator of larval fish

33 habitat quality as fatty acids are linked to fish larval growth and survival. We sampled an

34 anadromous fish nursery, the Chowan River, during spring of 2013 in order to determine how the

35 seston fatty acid composition varied in comparison with the zooplankton community

36 composition and fatty acid composition during the period of anadromous larval fish residency.

37 The seston fatty acid profiles showed no distinct pattern in relation to sampling time or location.

38 The mesozooplankton community composition varied spatially and the fatty acid profiles were

39 typical of freshwater species in April. The Chowan River experienced a saltwater intrusion event

40 during May, which resulted in brackish water species dominating the zooplankton community

41 and the fatty acid profile showed an increase in polyunsaturated fatty acids (PUFA), in particular

42 eicosapentaenoic acid (EPA) and docosahexaenoic acid (DHA). The saltwater intrusion event

43 was followed by an influx of freshwater due to high precipitation levels in June. The zooplankton

44 community composition once again became dominated by freshwater species and the fatty acid

45 profiles shifted to reflect this change; however, EPA levels remained high, particularly in the

46 lower river. We found correlations between the seston, microzooplankton and mesozooplankton

47 fatty acid compositions. Salinity was the main factor correlated to the observed pattern in species

48 composition, and fatty acid changes in the mesozooplankton. These data suggest that

49 anadromous fish nursery habitat likely experiences considerable spatial variability in fatty acid

50 profiles of zooplankton prey and that are correlated to seston community composition and

51 hydrodynamic changes. Our results also suggest that sufficient prey density as well as a diverse

52 fatty acid composition is present in the Chowan River to support larval fish production. 


\section{Introduction}

55

56

57 58

59

60

61

62

63

64

65

66

67

68

69

70

71

72

73

74

75

76

Estuaries are considered important nursery habitat for many ecologically and commercially important fish and invertebrates (Beck et al. 2001, Boesch and Turner 1984, Sheaves et al. 2015, Sheaves 2016). Estuaries function as fish nurseries because they are highly productive, support large planktonic populations across multiple size ranges, and fish within estuaries generally have higher growth rates compared to other habitats (Beck et al. 2001). Hence, many fish have evolved life-history strategies whereby larvae and juvenile stages have residency periods in estuaries (McHugh 1967; Boehlert and Mundy 1988; Beck et al. 2001; Able 2005; Walsh et al. 2005). Beck et al. (2001) defined nursery habitat as an area that contributes to higher production of individuals that move to juvenile habitat compared to other areas. Higher growth rates of larval fish are possible because of zooplankton prey that are present during their critical transition from yolk sac to free-living, feeding larvae (Hjort 1914; Mullen et al. 1986; Rulifson et al. 1993; Cooper et al. 1998; Martino and Houde 2010; Binon 2011). However, spatial and temporal overlap between predators and prey does not completely explain how fish nurseries function mechanistically. The quality of prey can play a major role in determining the effectiveness of a nursery for early stages of fish.

The quality (chemical composition) of zooplankton prey can influence fish growth, development, and survival (Fraser et al. 1989; Webster and Lovell 1990; Copeman et al. 2002; Rossi et al. 2006; Malzahn et al 2007, Paulsen et al. 2014). Fatty acids are chemically diverse, often incorporated into organisms unmodified, and different organisms have distinct profiles (Dalsgaard et al. 2003). Fatty acids are one class of compounds found in lipids that are particularly important, impacting neural and vision development in fish (Gulati et al. 1997; Müller-Navarra et al. 2000; Kainz et al. 2004; Masclaux et al. 2012). Fatty acids may act as both 
77 dietary tracers in the food web and indicators of overall food quality (Iverson et al. 2004). The

78 majority of organisms need specific dietary fatty acids for somatic development and fitness

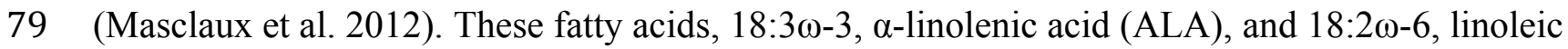

80 acid (LA), are labeled essential fatty acids because they cannot be directly synthesized by

81 heterotrophic organisms and must come from the diet (Arts et al. 2009). Polyunsaturated fatty

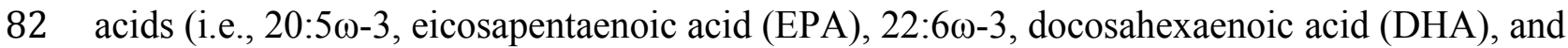

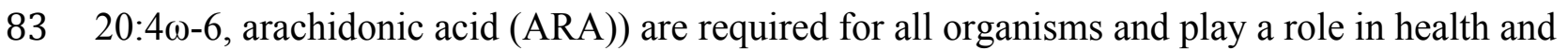

84 cell function (Dalsgaard et al. 2003). Thus, an organisms' fatty acid signature may indicate

85 dietary consumption and nutritional quality of its prey (Goncalves et al. 2012).

86

Fatty acids are present in estuaries as a result of de novo synthesis by phytoplankton and

87 the delivery of detrital material of plant origin (Dalsgaard et al. 2003). The free-floating portion

88 of organic and inorganic particles is termed seston (Postel et al. 2000). The organic portion of

89 seston is important because it forms the origin point for the propagation of fatty acids through the

90 pelagic food web. Zooplankton assimilate fatty acids from the seston through direct consumption

91 of phytoplankton cells, detritus and/or consumption of microzooplankton that graze

92 phytoplankton or detritus (Wacker and von Elert 2001; Kainz, Arts, and Mazumder 2004; Vargas

93 et al. 2006). To date, studies of the relationship between seston and zooplankton fatty acid

94 composition have shown variable patterns. Persson and Verde (2006) demonstrated in laboratory

95 studies that broad zooplankton taxonomic groups (cladoceran vs. copepods) have different fatty

96 acid profiles independent of the food source. The seston has been correlated to the fatty acid

97 profile of zooplankton in situ as well (Goulden and Place 1990; Brett et al 2006; Taipale et al.

98 2009; Gladyshev et al. 2010; Ravet, Brett, and Arhoditsis 2010). The mismatch of fatty acids in

99 seston to zooplankton has also been shown in many studies (Desvilettes et al. 1997; Persson and 
100 Vrede 2006; Rossi et al. 2006; Smyntek et al. 2008). Most marine zooplankton species cannot

101 convert precursor fatty acids and only obtain longer-chained fatty acids from their diet, compared

102 to freshwater zooplankton species that can convert precursor fatty acids (Rossi et al. 2006;

103 Persson and Verde 2006). However, it is clear that the fatty acid composition of the seston

104 changes as a result of local conditions, e.g., the salinity and temperature, nutrient concentration,

105 and the degree of autotrophy or heterotrophy in the system (Farkas and Herodek 1964;

106 Desvilettes et al. 1997; Wacker and von Elert 2001; Goncalves et al. 2012). Therefore,

107 combined knowledge of the changing nature of seston fatty acid composition, zooplankton

108 community composition changes, and fatty acid profiles forms a useful base for assessing the

109 quality of fish nursery habitat.

110 Zooplankton community composition in estuaries has been intensely studied and abiotic

111 factors are thought to structure zooplankton communities (Ambler et al. 1985; Orsi 1986;

112 Cervetto et al. 1999; Mouny and Dauvin 2002; Kimmel and Roman 2004; Lawrence et al. 2004;

113 Islam et al. 2005). Zooplankton community composition in temperate estuaries is dominated by

114 crustaceans in general, and copepods and cladocerans in particular (Tackx et al. 2004, Marques

115 et al. 2006; Winder and Jassby 2011; Chambord et al. 2016). Cladocerans are characterized by

116 high levels of EPA and ARA and this is thought to be related to a life history strategy focused on

117 high rates of somatic growth (Persson \& Vrede 2006). In contrast, copepods have higher relative

118 DHA levels because this fatty acid is critical for nervous system development (Arts et al. 2009).

119 Copepods feature more developed nervous systems compared to cladocerans and this is a

120 function of active hunting of prey, mate location, and predator avoidance (Dalsgaard et al. 2003).

121 Carnivorous crustacean zooplankton have shown to be richer in PUFAs and this is thought to be 
122 related to their food source (rotifers and smaller bodied cladoceran/copepods compared to

123 phytoplankton) (Arts et al. 2009).

124 Here we explore the species composition and variability in fatty acid composition of the

125 lower food web at the freshwater/saltwater interface of an estuarine fish nursery, the Chowan

126 River, North Carolina, USA. The Chowan River is considered a critical habitat for larval and

127 juvenile blueback herring (Alosa aestivalis), alewife (A. pseudoharengus), collectively known as

128 river herring (NCDMF 2007). The river herring are of interest because they have been severely

129 overfished and a moratorium on harvest is in place at various locations along the eastern United

130 States, including North Carolina (ASMFC 2012). The Chowan River also serves as a nursery

131 habitat for American shad (A. sapidissima) and striped bass (Morone saxatilis); however, the

132 status of the habitat for the latter species is unknown (Greene et al. 2009).

133 The overall goal of our study was to determine if species and fatty acid composition of

134 the lower food web could be used to indicate habitat quality of an estuarine fish nursery. In order

135 to achieve this goal, we examined the spatial and temporal variability in species composition of

136 microzooplankton and mesozooplankton as well as the fatty acid composition of the seston,

137 microzooplankton, and mesozooplankton during the period of larval fish residency in the

138 Chowan River. Our specific objectives were to determine: 1) if differences in the species

139 composition and fatty acid composition were present in the system; 2) if so, were there patterns

140 in species composition and fatty acid composition in time and space; 3) if particular species were

141 related to the species composition patterns and if particular fatty acids were related to the fatty

142 acid composition patterns; 4) if changes in species and fatty acid composition were related to

143 changes in salinity dynamics; 5) if patterns in fatty acid composition correlated across trophic

144 levels. We hypothesized that species composition would be related to salinity and that fatty acid 
145 profiles of micro- and mesozooplankton would relate to species composition and would reflect

146 that of the seston. If supported, this would suggest that the quality of the larval fish forage, based

147 on fatty acids, could be used to assess fish nursery quality.

\section{Materials and Methods}

149 Study Site

150 The Chowan River is one of the largest tributaries that drains into the Albemarle Sound

151 (Fig. 1a and 1b) and is the $12^{\text {th }}$ largest river basin in North Carolina (NCDENR 2006). It is

152 mainly a freshwater estuary that experiences intermittent salinity intrusion, mainly in the winter

153 months (Leech et al. 2009). The Chowan River was classified as "nutrient sensitive waters" in

1541979 (NCDENR 2006) and has routinely experienced algal blooms and low dissolved oxygen

155 levels $\left(<3.0 \mathrm{mg} \mathrm{L}^{-1}\right)$. The entire river is classified as a Strategic Habitat Area for larval and 156 juvenile river herring (NCDMF 2007). Sampling took place south of Holiday Island on a $34 \mathrm{~km}$

157 transect of Chowan River (Fig. 1c). Seven locations (4 km apart) were sampled between Holiday

158 Island and the river mouth (Fig 1c). Sampling occurred on 10-11 April, 31 May, and 25 June

159 2013, dates that span the residency for larvae of alewife, blueback herring, and striped bass. For

160 our study, we divided the river into three sections: upper, middle, and lower. The main

161 differences among these sections were (1) the distance from the Albemarle Sound and (2) the

162 potential influence of salinity.

163 Sample collection

164 Water column properties

165 Vertical profiles of temperature $\left({ }^{\circ} \mathrm{C}\right)$ and salinity were measured with a conductivity, 166 temperature, and depth sensor (CTD, Yellow Springs Instruments, Castaway). Water samples 167 were collected at a depth of 3 meters with a Niskin water sampler. 
168

169

170

171

172

173

174

175

176

177

178

179

180

181

182

183

184

185

186

187

188

\section{Zooplankton}

Water depths ranged from 5.27 to $7.56 \mathrm{~m}$ during zooplankton sampling. Two horizontal net tows were made with $0.5 \mathrm{~m}$ diameter nets of two different mesh sizes (60 and $200 \mu \mathrm{m})$. Two mesh sizes were used in order to generate an adequate representation of the zooplankton for the size range $>60 \mu \mathrm{m}$. The zooplankton samples between 60 and $200 \mu \mathrm{m}$ are designated microzooplankton and the $>200 \mu \mathrm{m}$ zooplankton samples are designated mesozooplankton throughout the remainder of the paper. The zooplankton net was towed obliquely through the water for 1 minute (species composition) and 2 minutes (fatty acid composition) at an average boat speed of $0.75 \mathrm{~m} \mathrm{~s}^{-1}$. The volume filtered was calculated using the volume of a cylinder ( $\left.V=\pi r^{2} L\right)$, where $r$ was the radius of the plankton net $(0.25 \mathrm{~m})$ and $L$ was determined using the boat speed $\left(\mathrm{m} \mathrm{s}^{-1}\right)$ and the tow time (s). Each identification and count sample, depending on mesh size, was filtered through a 60 or $200 \mu \mathrm{m}$ filter, and zooplankton for composition were preserved in a $120 \mathrm{~mL}$ glass jar with $10 \mathrm{ml}$ of $10 \%$ buffered formaldehyde, sucrose, and filtered water. The addition of sucrose to the formalin helps to reduce ballooning of cladoceran bodies and inflation of their carapace (Haney and Hall 1973). The $60 \mu \mathrm{m}$ sample had a half tablet of Alka Seltzer added to keep rotifers from pulling in critical body parts (legs and arms) to ease identification (Chick et al. 2010). The zooplankton samples for fatty acid analysis were collected at seven sites on the Chowan River for April and June, and three sites in May. Due to limitations related to sampling preparation in May, a subset of the field sites was sampled for fatty acid analyses. The zooplankton samples for fatty acids were placed in a $1000 \mathrm{~mL}$ plastic container on ice, and processed in the laboratory. 
189

190

191

192

193

194

195

196

197

198

199

200

201

202

203

204

205

206

207

208

209

210

211

Laboratory Processing

Zooplankton Identification

Samples were filtered through a sieve (60 or $200 \mu \mathrm{m})$ to remove the sugar formalin solution, and then added to a beaker with a known volume of water. A total of three subsamples ( $2 \mathrm{~mL}$ per subsample for microzooplankton and $5 \mathrm{~mL}$ per subsample for mesozooplankton) were analyzed for community composition using a Hensen-Stempel pipette. Organisms were identified using a dissecting microscope and enumerated using a Ward counting wheel. The zooplankton were identified to genus except for the freshwater copepods that were identified to order. Copepod nauplii were grouped together because identification can be difficult at this stage (Johnson and Allen 2012). If a species in a subsample comprised greater than 500 individuals, then that species was not counted for the other two subsamples. Species abundances $(A)$ were determined using the equation: $A=A_{s}\left(V_{t} V_{s}^{-1}\right)$ where $A_{s}$ is the number of individuals in the subsample, $V_{t}$ is the total volume of water in the beaker, and $V_{s}$ is the volume of the subsample.

\section{Lipid and fatty acid samples}

The water samples $(300 \mathrm{~mL})$ were concentrated on a $0.7 \mu \mathrm{m}$ Whatman ${ }^{\mathrm{TM}} \mathrm{GF} / \mathrm{F}$ filter $(47$ $\mathrm{mm}$ diameter) and stored at $-80^{\circ} \mathrm{C}$ until ready to process, which constituted the seston material. The zooplankton samples were filtered through 60 and $200 \mu \mathrm{m}$ sieves stacked to collect species based on size. Each sample was visually analyzed to determine the dominant species with a dissecting microscope, and detritus and phytoplankton were removed. The samples were concentrated on a GF/F filter ( $47 \mathrm{~mm}$ diameter $)$ by mesh size $(60,200 \mu \mathrm{m})$, and stored at $-80^{\circ} \mathrm{C}$ until ready to process.

Total lipids were extracted with chloroform-methanol $(2: 1, v / v)$ containing $0.01 \%$ butylated hydroxytoluene as an antioxidant (Folch et al. 1957). The organic solvent was 
212 evaporated under a stream of nitrogen and lipid concentration determined gravimetrically.

213 Transmethylation of fatty acids was done according to the method described by Metcalfe and

214 Schmitz (1969). A known amount of nonadecanoate acid (19:0) dissolved in hexane at a

215 concentration of $8 \mathrm{mg} \mathrm{ml}^{-1}(\mathrm{Nu}$ Check Prep Inc.) was added as internal standard. The fatty acid

216 methyl esters (FAME) were separated by gas chromatography (Agilent 7890A Gas

217 Chromatograph, Agilent Technologies, Inc.) using a 7693 mass spectrometer detector (Agilent

218 Technologies, Inc.), a capillary column (Omegawax ${ }^{\mathrm{TM}} 250$ fused silica capillary column, $30 \mathrm{~mm}$

$219 \times 0.25 \mathrm{~mm}$ and $0.25 \mathrm{~mm}$ film thickness, Supleco®), and a 7890A autoinjector (Agilent

220 Technologies, Inc.). Helium was used as the carrier gas at a flow of $1.3 \mathrm{ml} \mathrm{min}^{-1}$ and the

221 injection volume was $2 \mathrm{~mL}$. Initial temperature of the oven was $175^{\circ} \mathrm{C}$ for $26 \mathrm{~min}$, which was

222 increased to $205^{\circ} \mathrm{C}$ by increments of $2^{\circ} \mathrm{C} \mathrm{min}{ }^{-1}$, then held at $205^{\circ} \mathrm{C}$ for $24 \mathrm{~min}$. The source and

223 analyzer for the mass spectrometer was set at $230^{\circ} \mathrm{C}$. The individual fatty acid methyl esters were

224 identified by comparing the retention times of authentic standard mixtures (FAME mix 37

225 components, Supleco) and quantified by comparing their peak areas with that of the internal

226 standard (Czesny and Dabrowski 1998). The results of individual fatty acid composition are

227 expressed in percentage of total identified FAME.

228 Statistical Analysis

229 We performed a series of multivariate analyses to address our specific objectives. We

230 used PERMANOVA a part of the PRIMER 6 statistical software package (Clarke and Gorley

231 2006), to test for overall differences between the microzooplankton and mesozooplankton

232 community composition, and fatty acid profiles of seston, microzooplankton, and

233 mesozooplankton. PERMANOVA is a non-parametric technique related to ANOVA, but uses

234 permutations and fewer assumptions compared to the traditional ANOVA approach (Anderson 
235 2001). As such, it is particularly well suited to multivariate data sets that violate the traditional

236 assumptions of ANOVA and also have low sample sizes, as was our case (Anderson 2001).

237 If PERMANOVA detected differences, we then generated separate, Bray-Curtis

238 similarity matrices for microzooplankton species composition (60 $\mu \mathrm{m}$ mesh), mesozooplankton

239 species composition (200 $\mu \mathrm{m}$ mesh), seston fatty acid composition, microzooplankton fatty acid

240 composition, and mesozooplankton fatty acid composition. A separate cluster analysis was

241 performed using PRIMER 6 in order to reveal patterns over time and space for each similarity

242 matrix. Each individual sample was associated with a location in the river (upper, middle, lower)

243 and month (April, May, June) and these labels were used for visualization of samples in the

244 cluster dendrogram. Next, a similarity percentage analysis (SIMPER) test was used to compare

245 similarities within groups and determine the species or fatty acids that contributed to each

246 grouping from the cluster analysis (Clarke and Gorley 2006). The SIMPER test was set at 70\%

247 cumulative contribution.

248 We then wanted to determine if salinity and temperature were related to the observed

249 patterns and we used redundancy analysis for this purpose (Legendre and Legendre 1998). The

250 redundancy analysis was carried out in the $\mathrm{R}$ environment ( $\mathrm{R}$ v3.2.3, R Core Development Team

251 2015) using rda function (Oksanen et al. 2013) in the vegan package (Oksanen et al. 2017).

252 Finally, we used a Mantel matrix comparison to correlate fatty acid profiles between the three

253 groups (seston, microzooplankton, and mesozooplankton). The mantel.rtest function in the ade4

254 package (Oksanen et al. 2017) in the R environment (R v3.2.3, R Core Development Team 2015)

255 was used.

256 Results

257 Salinity and Temperature 
259 in the upper river remained low (0.07), but the water column became stratified in the middle and

260 lower river, with salinities ranging from $0.28-1.66$. The river returned to freshwater (0.04 to

261 0.08) again in June due to a tropical storm that brought heavy rains for a two-week period. North

262 Carolina experienced the second wettest June since 1895 with rainfall that ranged from 15.2 to

$26319.05 \mathrm{~cm}$ in the study area (Hiatt 2013). Water temperatures increased during the study period

264 April $\left(15.7 \pm 1.1^{\circ} \mathrm{C}\right)$, May $\left(24.0 \pm 1.0^{\circ} \mathrm{C}\right)$ and June $\left(26.2 \pm 0.3^{\circ} \mathrm{C}\right)$.

\section{Zooplankton Community Composition}

266 There were significant differences between the overall microzooplankton and

267 mesozooplankton community composition (PERMANOVA, $p=0.001$ ). Microzooplankton could

268 be separated into two distinct groups by cluster analysis at 65\% similarity (Figure 2a). Group 1

269 consisted of the vast majority of the samples collected across April, May, and June throughout

270 the river (Figure 2a). Group 2 consisted of two samples collected in the middle and lower river in

271 June (Figure 2a). Both groups were dominated by rotifers and copepod nauplii, but group 2 had a

272 higher contribution of copepod nauplii (Figure $2 \mathrm{~b}$ and Table 1).

273 Three groups of mesozooplankton were differentiated at 50\% similarity using cluster

274 analysis (Figure 3a). Group 3 consisted of samples from the May collection only, Group 4

275 consisted of a mixture of April and June samples in primarily the upper and middle river, and

276 Group 5 consisted of one April upper site, May upper river section and June samples throughout

277 the river (Figure 3a). Group 3 mesozooplankton percent composition was dominated by Acartia

278 spp. with a minor contribution by Bosminidae, Group 4 consisted primarily of equivalent

279 percentages of Cyclopoida and Bosminidae, and Group 5 mesozooplankton percent community 
280 composition was characterized by higher percentages of Leptodora spp. and Calanoida (Figure

$2813 \mathrm{~b}$ and Table 1).

282 Fatty Acid Composition

283 A total of 24 specific fatty acids were found in all samples (Tables A1-A3). Fatty acids

284 were first separated into broad categories: saturated fatty acids (SFA), monounsaturated fatty

285 acids (MUFA), and polyunsaturated fatty acids (PUFA) (Figure 4a). Seston had a higher percent

286 of SFA, and lower percent of MUFA and PUFA compared to micro- and mesozooplankton

287 (Figure 4a). Mesozooplankton and microzooplankton had a similar percent composition of SFA,

288 MUFA, and PUFA (Figure 4a). There were eight dominant fatty acids found in all the samples,

289 but the percent composition varied (Figure 4b). The most common SFA was palmitic acid (16:0),

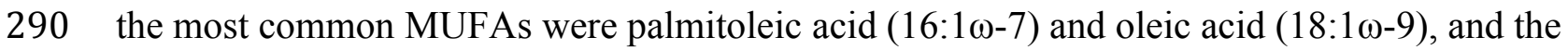

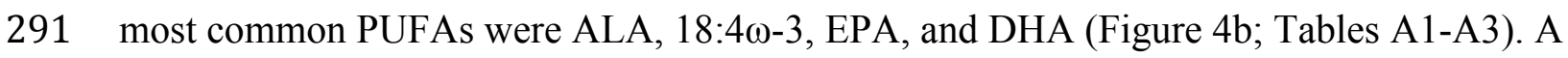

292 comparison of MUFAs and PUFAs among the seston and zooplankton showed that seston had

293 the lowest overall percentages of MUFAs and PUFAs (PERMANOVA, $p=0.001$, Figure 4b).

294 There was a difference between the microzooplankton fatty acid profile and the

295 mesozooplankton fatty acid profile (PERMANOVA, $p=0.025)$. The microzooplankton fatty

296 acid profile was characterized by a higher percentage of 18:1 $\omega-9$ compared to the other MUFAs

297 and PUFAs. In contrast, the mesozooplankton had the highest percent composition attributed to

298 two PUFAs, EPA and DHA (Figure 4b).

299 Seston

300 Three groups were designated at $60 \%$ similarity using cluster analysis for the seston fatty

301 acid composition (Figure 5a). The groups showed no distinct pattern in terms of sampling time or

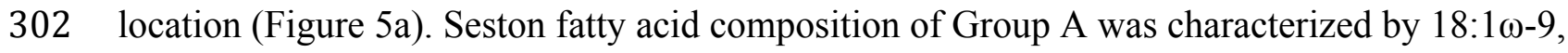


$30316: 1 \omega-7$, ALA, and EPA, Group B by 16:1 $\omega-7,18: 1 \omega-9,18: 2 \omega-6$ and EPA, and Group C had

304 similar percentage composition of MUFAs and PUFAs, except 18:2 $\omega-6$ (Figure 5b and Table 2).

305 Microzooplankton

306 Three groups were designated at $70 \%$ similarity using cluster analysis for the

307 microzooplankton fatty acid composition (Figure 6a). The groups segregated temporally, with

308 Group D and E consisting of April samples only, and Group F consisted of May and June

309 samples only (Figure 6a). The Group D fatty acids were dominated by 18:1 $\omega-9$ and to a lesser

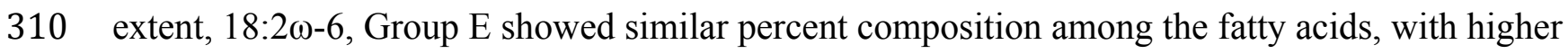

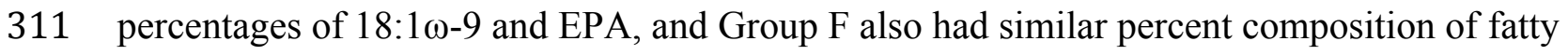

312 acids; however, the PUFAs EPA and DHA had significant contribution (Figure $6 \mathrm{~b}$ and Table 2).

313 Mesozooplankton

$314 \quad$ Four groups were designated by cluster analysis at $77 \%$ similarity for the

315 mesozooplankton fatty acid composition (Figure 7a). Groups G and I consisted of April samples

316 only whereas Group J consisted of May and June samples only (Figure 7a). Group H showed

317 spatial separation, consisting of primarily upper river locations across all of the months (Figure

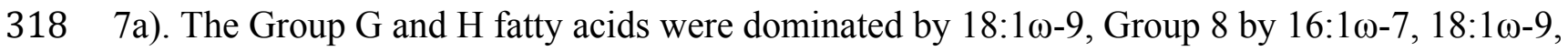

319 and EPA, Group I had similar percentages of fatty acids with ALA, DHA and EPA having higher

320 percentages, and Group J had DHA and EPA as dominant components of the fatty acids (Figure

$3217 \mathrm{~b}$ and Table 2).

322 Redundancy analysis and Mantel matrix correlations

323 Salinity was the main factor found to be correlated to observed patterns in the species

324 composition of both microzooplankton and mesozooplankton (Redundancy, $p=0.004$ ).

325 However, salinity was not correlated to changes in the seston (Redundancy, $p=0.490$ ) or 
326 microzooplankton (Redundancy, $p=0.27$ ) fatty acid profiles. Salinity was associated with the

327 changes in the mesozooplankton fatty acid profiles (Redundancy, $p=0.034)$. Seston fatty acid

328 profiles were correlated to the microzooplankton fatty acid profiles $(p=0.013)$ based on the

329 Mantel matrix comparison, but not correlated to the mesozooplankton fatty acid profiles $(p=$

330 0.340). The microzooplankton fatty acid profiles were correlated to the mesozooplankton fatty

331 acid profiles (Mantel, $p=0.059$ ).

\section{Discussion}

We found temporal and spatial differences in the species and fatty acid composition of

334 the lower food web that were mainly related to a salinity intrusion that occurred during the study

335 period during May. Prior to the salinity intrusion, larval fish would have encountered a

336 freshwater plankton assemblage that was dominated by rotifers, Bosminidae, and cylopoid

337 copepods throughout the river. This assemblage was proportionally higher in EPA relative to

338 DHA. During the salinity intrusion, the microzooplankton remained dominated by rotifers;

339 however, the mesozooplankton community became dominated by the copepod Acartia spp..

340 Concurrently, the proportion of DHA increased and remained elevated into June, particularly in

341 the middle and lower river. The intrusion of saline water increased the overall proportion of

342 omega-3 fatty acids in the River, presumably due to the increased fraction of micro- and

343 mesozooplankton feeding on a more marine-like phytoplankton based food web and this signal

344 propagated through the food web. Additionally, we observed that FA appeared to be

345 incorporated relatively unchanged in micro and mesozooplankton in terms of relative

346 composition; however, MUFA and PUFA percent compositions increased in zooplankton

347 relative to seston. This suggested that MUFA and PUFA are bioaccumulated at higher trophic

348 levels, as seen in other studies (Persson and Verde 2006; Gladyshev et al. 2010; Ravett, Brett, 
349 Arhonditsis 2010; Burns, Brett, and Schallenberg 2011). Overall, the FA composition of the food

350 web indicated that the Chowan River is likely to provide nutrition in terms of FA composition

351 for larval fish growth and development. This is based on the presence of higher chain $(>20$

352 carbons) PUFAs present in the mesozooplankton throughout the nursery.

353 The seston fatty acid composition consisted mainly of saturated fatty acids. Seston from

354 freshwater and estuarine systems typically has a large percentage of SFA and this fraction has

355 been attributed to detrital input, as opposed to originating from phytoplankton (Persson and

356 Vrede 2006; Gladyshev et al. 2010; Ravett, Brett, Arhonditsis 2010; Burns, Brett, and

357 Schallenberg 2011; Gonclaves et al 2012). Müller-Navarra et al. (2004) and Bec et al. (2010)

358 analyzed seston and found phytoplankton only explained $27 \%$ of variance in FA composition

359 and concluded that detritus and heterotrophic organisms also needed to be considered (Müller-

360 Navarra et al. 2004; Bec et al. 2010). Bec et al (2010) therefore concluded that the seston can

361 affect the fatty acid profiles of higher organisms, but may not relate individual groups of

362 phytoplankton or microzooplankton. This agreed with our findings as seen in the reduced

363 correlations between seston and the mesozooplankton.

364 We did not examine the seston composition directly by counting phytoplankton cells or

365 examining pigment concentrations, thus we were unable to attribute the origin of particular fatty

366 acids to phytoplankton or other sources. However, we were able to use the available literature to

367 identify potential indicators of fatty acid origin. The top four fatty acids by percent composition

368 varied by group, but 16:1 $\omega-7,18: 1 \omega-9,18: 2 \omega-6$, and ALA were the most prevalent. Potential

369 phytoplankton sources for these fatty acids may be diatoms, which have been shown to have

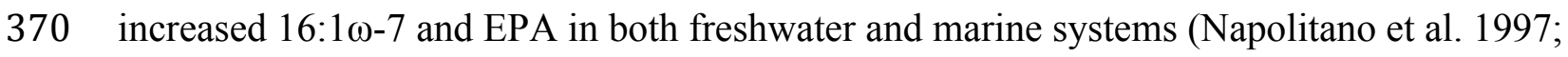

371 Dalsgaard et al. 2003; Boschker et al. 2005; Arts et al. 2009; Bec et al. 2010) and we observed 
372 this occurred in May and June coincident with the salinity increase. Green algae (Chlorophytes)

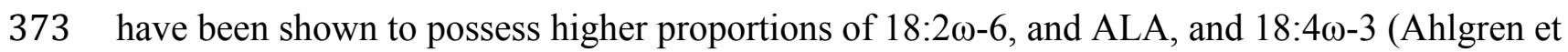

374 al. 1990; Dalsgaard et al. 2003; Boschker et al. 2005; Masclaux et al. 2012; Strandberg et al.

375 2015). Fatty acids corresponding to these phytoplankton groups were observed during April

376 throughout the river and June in the middle and upper river. One other source of seston FA may

377 have been present, pine pollen, which is found in large quantities during spring. Pine pollen is

378 transported to freshwater systems via aerial deposition and floats at the surface, and the pine

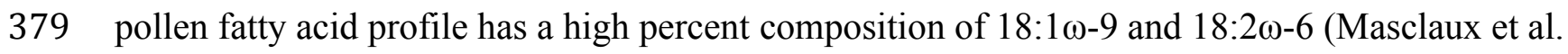

380 2013), which can be observed in our samples. Obviously, seston FA are a mixture of multiple

381 sources, thus the variability seen across the groups identified by the cluster analysis would be

382 expected.

383 The microzooplankton fatty acid profiles were different throughout the sampling period

384 with a change from decreased omega-3s to increased omega-3s in the system. This suggests a

385 switch in microzooplankton diet had occurred over the sampling period and two pathways appear

386 to be present during the study. The April microzooplankton fatty acid profiles for all river

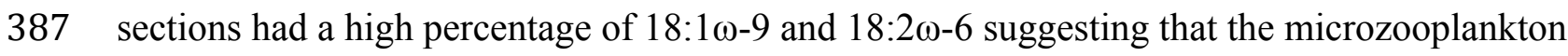

388 could be consuming either terrestrial material or chlorophytes during this time. Two sites in

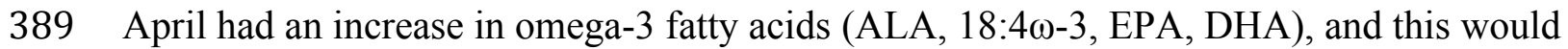

390 suggest a different dietary pathway that was reduced in SFA, perhaps consisting of either smaller

391 microzooplankton such as ciliates or phytoplankton such as diatoms and/or dinoflagellates (Park

392 and Marshall 2000; Gladyshev et al. 2010). The community was dominated by rotifers during

393 this time and communities high in rotifer abundance have been shown to closely reflect the

394 seston composition (Gladyshev et al. 2010). The microzooplankton fatty acid profiles in May 


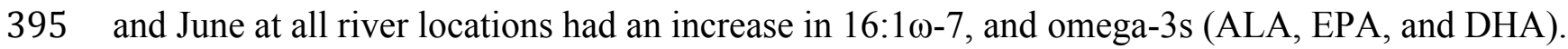

396 These changes can be correlated to the likely increase in diatoms and dinoflagellates from the

397 saltwater intrusion event. The changes in June could be the increase in copepod nauplii of

398 Calanoid copepods, and the presence of dinoflagellates and diatoms even when the system

399 returned to freshwater. Our results are similar to systems where the phytoplankton composition

400 was represented by diatoms and dinoflagellates by having increased 16:1 $\omega-7$ and PUFAs

401 (Müller-Navara et al. 2000; Dalsgaard et al. 2003; Gladyshev et al. 2010; Ravett, Brett,

402 Arhonditsis 2010).

403 The mesozooplankton fatty acid profiles throughout the river in April and in the upper

404 river in May and June were defined by higher percentages of 16:1 $\omega-7,18: 1 \omega-9$, ALA, EPA, and

405 DHA, and mixed mesozooplankton community consisting of cladoceran and copepods. These

406 fatty acids profiles are similar to those found in freshwater systems that have a mixed

407 zooplankton composition (Persson and Verde 2006; Arts et al. 2009; Kainz et al. 2009;

408 Gladyshev et al 2010; Burns et al. 2011; Masclaux et al. 2012). Cladocerans have low or no

409 DHA compared to copepods and high EPA levels have been shown to correlate with the high

410 somatic growth rates of cladoceran (Persson and Verde 2006). A saltwater intrusion changed the

411 mesozooplankton species composition in May resulting in numerical dominance by Acartia spp.

412 in the lower and middle sections of the river. Acartia spp. is the dominant copepod species in

413 temperate, estuarine systems (Ambler et al. 1985; Orsi 1986; Cervetto et al. 1999; Mouny and

414 Dauvin 2002; Kimmel and Roman 2004; Lawrence et al. 2004; Islam et al. 2005). The

415 mesozooplankton fatty acid profiles in May were represented by 16:1 $\omega-7$, EPA, and the highest

416 observed percentages of DHA. This is clearly a reflection of the dominance of Acartia spp. in

417 the system and a diet primarily consisting of marine algae higher in omega-3 FAs (Stottrup et al. 
418 1999; Persson and Verde 2006; Arts et al. 2009; Kainz et al. 2009; Gladyshev et al 2010;

419 Masclaux et al. 2012). Mesozooplankton fatty acid percent composition in June at the lower and

420 middle site remained similar to that observed in May, despite the species composition having

421 returned to a mix of cladocerans and copepods. This suggests that physical shifts in the system

422 that result in seston changes may persist in the system despite shifts in zooplankton community

423 composition.

424 The relevance of the food web fatty acid composition can be determined by examining

425 the potential feeding behavior of larval fish within the Chowan River nursery. Alewife and

426 blueback herring start feeding on smaller cladocerans and copepods at about $6 \mathrm{~mm}$ total length

427 (Mullen et al. 1986). Binon (2011) reported that river herring at $6 \mathrm{~mm}$ notochord length had a

428 maximum gape width of $400 \mu \mathrm{m}$, and estimated maximum prey size of $200 \mu \mathrm{m}$, which would

429 result in mesozooplankton being an important food resource. In the Connecticut River, the diet

430 for blueback herring were dominated by rotifers for fish 5-12 mm, Bosminidae for fish 12-16

$431 \mathrm{~mm}$, and cyclopoid copepods for fish $>16 \mathrm{~mm}$ in total length (Crecco and Blake 1983). Based on

432 these dietary studies, the larval and juvenile river herring would be feeding across the size range

433 of zooplankton prey that we sampled; however, fish would be consuming primarily

434 microzooplankton early in the year (April) and mesozooplankton later in the season (May and

435 June). In April, two pathways for FA propagation were present in the microzooplankton. Thus,

436 fish feeding during this time may experience variability in the quality of the microzooplankton

437 prey in terms of percentage of PUFAs. Larval fish need PUFAs (ALA, EPA and DHA) for

438 growth, visual acuity, survival, and development of normal pigmentation (Bell et al. 1995; Bell

439 and Sargent 1996; Rainuzzo et al. 1997; Sargent et al. 1999; Rossi et al. 2006). The shift to larger

440 prey later in the year (May and June) resulted in a change in prey quality as the relative 
441 percentage of EPA and DHA increased. This was the result of a salinity intrusion into the middle

442 and lower reaches of the estuary that was associated with dominance of the cladoceran Acartia

443 spp. and a significant increase in DHA and EPA. This could allow larval and juvenile fish to

444 consume prey with a higher proportion of PUFAs. It is unknown if river herring can elongate

445 precursor FA into PUFAs. Even if fish can convert precursor FA, larval fish could not receive all

446 nutritional need for those fatty acids (Agaba et al. 2005). The larval fish would not have to use

447 energy for the conversion, and could continue to put energy into growth (Wacker and von Elert

448 2001; Rossi et al 2006). This allows the larval fish to survive and grow past the critical period.

449 The fish nursery present in the lower Chowan River may undergo significant changes

450 during the critical time of larval fish growth and our results demonstrate how changes in the

451 seston community may propagate through the food web. The results also highlight that additional

452 information concerning the fatty acid composition of the zooplankton prey base for larval fish

453 can provide insight into habitat quality, our stated goal. Sheaves et al. (2004) pointed out the

454 need to expand the nursery habitat concept to include relevant ecosystem processes, particularly

455 resource dynamics. This research begins to explore the mechanisms that allow nursery habitat to

456 function. We plan further research to investigate the linkage between the seston community fatty

457 acid composition, the zooplankton community fatty acid composition, and larval fish to

458 determine how lower food web variability relates to larval fish condition and survival.

\section{Acknowledgements}

460 I would like to thank S. Lichti, C. Krahforst, J. Osborne, A. Powell, M. Baker, and E. Diaddorio

461 for help in the field collection. I would like to thank L. Stratton, C. Kolb, and R. Pattridge for

462 help in Dr. Jacques Rinchard's lab in processing my fatty acid samples. I would like to thank Dr. 
463 Ariane Peralta for help with the improved statistical analysis, and two anonymous reviewers for 464 comments, which helped to improve the manuscript. 
465 Work Cited

466 Able, K.W. (2005) A re-examination of fish estuarine dependence: Evidence for connectivity

467 between estuarine and ocean habitats. Estuarine, Coastal, and Shelf Science 64: 5-17.

468 Agaba, M.K., D.R. Tocher, X.Z. Zheng, C.A. Dickson, J.R. Dick, and A.J. Teale. (2005) Cloning

469 and functional characterization of polyunsaturated fatty acid elongates of marine and freshwater

470 teleost fish. Journal of Comparative Physiology B 142: 342-352.

471 Ahlgren, G., L. Lundstedt, M. Brett, and C. Forsberg. (1990) Lipid composition and food quality

472 of some freshwater phytoplankton for cladoceran zooplankters. Journal of Plankton Research 12:

473 809-818.

474 Ambler, J.W., J.E. Cloern, and A. Hutchinson. (1985) Seasonal cycles of zooplankton from San

475 Francisco Bay. Hydrobiologia 129: 177-197.

476 Anderson, M. J. (2001), A new method for non-parametric multivariate analysis of variance.

477 Austral Ecology, 26: 32-46. doi:10.1111/j.1442-9993.2001.01070.pp.x

478 Arts, M.T., M.T. Brett, and M.J. Kainz. (2009) Lipids in aquatic ecosystems. Springer. New

479 York, New York.

480 ASMFC (Altantic States Marine Fisheries Commission). (2012) River herring benchmark stock

481 assessment volume 1. Stock Assesment Report No. 12-02, May 2012.

482 Beck, M.W., K.L. Heck Jr., K.W. Able, D.L. Childers, D.B. Eggleston, B.M. Gillanders, B.

483 Halpern, C.G. Hays, K. Hoshino, T. J. Minello, R.J. Orth, P.F. Sheridan, and M.P. Weinstein.

484 (2001) The identification, conservation, and management of estuarine and marine nurseries for

485 fish and invertebrates. BioScience 51: 633- 641.

486 Bell, M.V., R.S. Batty, J.R. Dick, K. Fretwell, J.C. Navarro and J.R. Sargent. (1995) Dietary

487 deficiency of docosahexanenoic acid impairs vision at low light intensities in juvenile herring

488 (Clupea harengus L.). Lipids 30 (5): 443-449.

489 Bec, A., M.E. Perga, C. Desvilettes, and G. Bourdier. (2010) How well can the fatty acid content

490 of lake seston be predicted from its taxonomic composition? Freshwater Biology 55: 1985-1972.

491 Bell, M.V. and J.R. Sargent. (1996) Lipid nutrition and fish recruitment. Marine Ecology

492 Progress Series 134: 315-316.

493 Binion, S. (2011) Evaluating spatial and temporal overlap between larval alosines and potential

494 zooplankton prey in lower Roanoke River and Albemarle Sound, North Carolina. Thesis. East

495 Carolina University, Greenville, NC.

496 Boehlert, G.W. and B.C. Mundy. (1988) Role of behavioral and physical factors in larval and

497 juvenile fish recruitment to estuarine nursery areas. American Fisheries Society Symposium

498 3:51-67.

499 Boesch, D.F., and R.F. Turner. (1984) Dependence of fisheries species on salt marshes: the role

500 of food and refuge. Estuaries and Coasts 7: 460-468.

501 Boschker, H.T., J.C. Krombamp, and J.J. Middelburg. (2005) Limnology and Oceanography 50:

502 70-80.

503 Brett, M.T. and D.C. Müller-Navarra. (1997) The role of highly unsaturated fatty acids in aquatic

504 foodweb processes. Freshwater Biology 38: 483-499.

505 Brett, M.T., D.C. Müller-Navarra, A.P. Ballantyne, J.L. Ravet, C.R. Goldman. (2006) Daphnia

506 fatty acid composition reflects that of their diet. Limnology and Oceanography 51: 2428-2437.

507 Burns, C., M.T. Brett, and M. Schallenberg. (2010) A comparison of the trophic transfer of fatty

508 acids in freshwater plankton by cladocerans and calanoid copepods. Freshwater Biology 56:889-

509903. 
510 Cervetto, G., R. Gaudy, and M. Pagano. (1999) Influence of salinity on the distribution of 511 Acartia tonsa (Copepoda, Calanoida). Journal of Experimental Marine Biology and Ecology 512 239: 33-45.

513 Chambord, S., T. Maris, F. Colas, T. van Engeland, A.C. Sossu, F. Azemar, M. Le Coz, T. Cox, 514 L. Buisson, S. Souissi, P. Meire, and M. Tackx. (2016) Mesozooplankton affinities in a 515 recovering freshwater estuary. Estuarine, Coastal, and Shelf Science 177: 47-59.

516 Chick, J.H. and M.J. Van Den Avyle. (1999) Effects of zooplankton spatial variation on growth 517 of larval striped bass: an experimental approach. Transactions of the American Fisheries Society 518 128: 339-351.

519 Chick, J.H., A.P. Levchuk, K.A. Medley and J.H. Havel. (2010) Underestimation of rotifer 520 abundance a much greater problem than previously appreciated. Limnology and Oceanography: 521 Methods 8, 79-87.

522 Clarke, K.R. and R.N. Gorley. (2006) Primer V6: User Manual/Tutorial. Primer-E Ltd.

523 Plymouth, United Kingdom.

524 Cooper, J.E., R.A. Rulifson, J.J. Isely, S.E. Winslow. (1998) Food habits and growth of juvenile 525 striped bass, Morone saxatilis, in Albemarle Sound, North Carolina. Estuaries 21: 307-317.

526 Copeman, L.A., C.C. Parrish, J.A. Brown, M. Harel. (2002) Effects of docosahexaenoic, 527 eicosapentaenoic, and arachidonic acids on the early growth, survival, lipid composition and 528 pigmentation of yellowtail flounder (Limanda ferruginea): a live food enrichment experiment.

529 Aquaculture 210: 285-304.

530 Czesny, S. and K. Dabrowski. (1998) The effect of fatty acids concentration in wild and 531 domesticated walleye (Stizostedion vitreum) eggs on embryos' viability. Aquatic Living 532 Resources 11: 371-378.

533 Dalsgaard, J., M. St. John, G. Kattner, D. Müller-Navarra and W. Hagen. (2003) Fatty acids 534 trophic markers in the pelagic marine environment. Advances in Marine Biology 46: 225-340.

535 Desvilettes, C.H., G. Bourdier, C.H. Amblard and B. Barth. (1997) Use of fatty acids for the 536 assessment of zooplankton grazing on bacteria, prtozoans and microalgae. Freshwater Biology 537 38, 629-637.

538 Farkas, T., and S. Herodek. (1964) The effect of environmental temperature on the fatty acid 539 composition of crustacean plankton. Journal of Lipid Research 5: 369-373.

540 Folch, J., M. Lees, and G.H. Sloane Stanley. (1957) A simple method for isolation and 541 purification of total lipids from animal tissues. Journal of Biological Chemistry 226: 497-509. 542 Fraser, A.J., J.R. Sargent, J.C. Gamble, and D.D. Seaton. (1989) Formation and transfer of fatty 543 acids in an enclosed marine food chain comprising phytoplankton, zooplankton, and herring 544 (Clupea harengus L.) larvae. Marine Chemistry 27: 1-18.

545 Gladyshev, M.I., N.N. Sushchik, O.N. Makhutova, O.P. Dubovskaya, E. S. Kravchuk, and E.B. 546 Khromechek. (2010) Correlations between fatty acid composition of seston and zooplankton and 547 effects of environmental parameters in a eutrophic Siberian reservoir. Limnologica 40: 343-357. 548 Goncalves, A.M.M., U.M. Azeiterio, M.A. Pardal and M. De Troch. (2012) Fatty acid profiling 549 reveals seasonal and spatial shifts in zooplankton diet in a temperate estuary. Estuarine, Coastal 550 and Shelf Science 109: 70-80.

551 Goulden, C.E. and A.R. Place. (1990) Fatty acid synthesis and accumulation rates in daphniids. 552 Journal of Experimental Zoology 256: 168-178.

553 Greene, K.E., J.L. Zimmerman, R.W. Laney, and J.C. Thomas-Blate. (2009) Atlantic coast 554 diadromous fish habitat: A review of utilization, threats, recommendations for conservation, and 
555 research needs. Atlantic States Marine Fisheries Commission Habitat Management Series No. 9, 556 Washington, D.C.

557 Gulati, R.D. and W.R. Demott. (1997) The role of food quality for zooplankton: remarks on the

558 state-of-the-art, perspectives and priorities. Freshwater Biology 38: 753-768.

559 Haney, J.F. and D.J. Hall. (1973) Sugar-coated Daphnia: A preservation technique for Cladocera.

560 Limnology and Oceanography 18: 331-333.

561 Hiatt, Ashley. (2013) Climate Summary: June 2013. State Climate Office of North Carolina.

562 http://nc-climate.ncsu.edu/climateblog?id=28. Accessed 15 September 2013.

563 Hjort, J. (1914) Fluctuations in the great fisheries of northern Europe viewed in the light of

564 biological research. Rapp. P.-v. Reun. Cons. Perm. lnt. Explor. Mer. 29: 1-228.

565 Islam, M.S., H. Ueda, and M. Tanaka. (2005) Spatial distribution and trophic ecology of

566 dominant copepods associated with turbidity maximum along the salinity gradient in a highly

567 embayed estuarine system in Ariake Sea, Japan. Journal of Experimental Marine Biology and

568 Ecology 316: 101-115.

569 Iverson, S.J., C. Field, W.D. Bowen, and W. Blanchard. (2004) Quantitative fatty acid signature

570 analysis: a new method of estimating predator diets. Ecological Monographs 74: 211-235.

571 Johnson, W.S. and D.M. Allen. (2012) Zooplankton of the Atlantic and Gulf coasts: a guide to

572 their identification and ecology, $2^{\text {nd }}$ edition. John Hopkins University Press. Baltimore,

573 Maryland.

574 Kainz, M., M.T. Arts and A. Mazumder. (2004) Essential fatty acids in the planktonic food web

575 and their ecological role for higher trophic levels. Limnology and Oceanography 49: 1748-1793.

576 Kainz, M.J., M. Perga, M.T. Arts and A. Mazumder. (2009) Essential fatty acid concentration of

577 different seston sizes and zooplankton: a field study of monomictic coastal lakes. Journal of

578 Plankton Research 31: 635-645.

579 Kimmel D.G., and M.R. Roman. (2004) Long-term trends in mesozooplankton abundance in

580 Chesapeake Bay USA: influence of freshwater input. Marine Ecology Progress Series 267: 71-

58183.

582 Kimmerer, W.J. (2002) Effects of freshwater flow on abundance of estuarine organisms:

583 physical effects or trophic linkages? Marine Ecology Progress Series 243: 39-55.

584 Lawrence, D., I.Valiela, and G. Tomasky. (2004) Estuarine calanoid copepod abundance in

585 relation to season, salinity, and land-derived nitrogen loading, Waquoit Bay, MA. Estuarine,

586 Coastal and Shelf Science 61: 547-557.

587 Leech, D., S. Ensign and M. Piehler. (2009) Zooplankton Assessment Project (ZAP):

588 Reassessing prey availability for river herring in the Chowan River Basin- Year 2. North

589 Carolina Sea Grant Report. FRG 08-EP-06/ 09-EP-03.

590 Legendre P., Legendre L. (1998) Numerical Ecology. 2nd Ed. Amsterdam: Elsevier

591 Malzahn, A.M., N. Aberle, C. Clemmesen, and M. Boersma. (2007) Nutrient limitation of

592 primary producers affects planktivorous fish condition. Limnology and Oceanography 52: $2062-$

5932071.

594 Marques, S.C., U.M. Azeiteiro, J. C. Marques, J. M. Neto, and M.A. Pardal. 2006. Zooplankton

595 and icthyoplankton communities in a temperate estuary: spatial and temporal patterns. Journal of

596 Plankton Research 28: 297-312.

597 Martino, E.J. and E.D. Houde. (2010) Recruitment of striped bass in Chesapeake Bay: spatial

598 and temporal environmental variability and availability of zooplankton prey. Marine Ecology

599 Progress Series 409: 213-228. 
600 Masclaux, H., A. Bec, M.J. Kainz, F. Perriere, C. Desvilettes and G. Bourdier. (2012)

601 Accumulation of polyunsaturated fatty acids by cladocerans: effects of taxonomy, temperature

602 and food. Freshwater Biology 57: 696-703.

603 Masclaux, H., M.E. Perga, M. Kagami, C. Desvilettes, G. Bourdier, and A. Bec. (2013) How

604 pollen organic matter enters freshwater food web. Limnology and Oceanography 58: 1185-1195.

605 McHugh, J.L. (1967) Estuarine nekton. American Association for the Advancement of Science

606 Publications 83: 581-620.

607 Metcalfe, L.D and A.A. Schmitz. (1961) The rapid preparation of fatty acid esters for gas

608 chromatographic analysis. Analytical Chemistry 33: 363-364.

609 Moderan, J., V. David, P. Bouvais, P. Richard and D. Fichet. (2012) Organic matter exploitation

610 in a highly turbid environment: planktonic food web in the Charente estuary, France. Estuarine,

611 Coastal Shelf Science 98: 126-137.

612 Mouny, P. and J.C. Dauvin. (2002) Environmental control of mesozooplankton community

613 structure in the Seine estuary (English Channel). Oceanologica Acta 25: 13-22.

614 Mullen, D.M., C.W. Fay, and J.R. Moring. (1986) Species profiles: life history and

615

616

617

618

619 environmental requirements of coastal fishes and invertebrates (North Atlantic) alewife/blueback herring. Biological Report 82. USFWS and Army Corps of Engineers.

Müller-Navarra, D.C., M.T. Brett, A.M. Liston and C.R. Goldman. (2000) A highly unsaturated fatty acid predicts carbon transfer between primary producers and consumers. Nature 403: 74-77. Müller-Navarra, D.C., M.T. Brett, S. Park, S. Chandra, A. P. Ballantyne, E. Zorita, and C.R.

620

621 Goldman. 2004. Unsaturated fatty acid content in seston and tropho-dynamic coupling in lakes.

622

623 Nature 427: 69-72.

Müller-Navarra, D. (2008) Food web paradigms: the biochemical view on trophic interactions. International Review Hydrobiology 93: 489-505. acid as trophic markers of phytoplankton blooms in the Bahia Blanca Estuary (Buenos Aires, Argentina) and in Trinity Bay (Newfoundland, Canada). Biochemical Systematics and Ecology 25: 739-755.

NCDENR (North Carolina Department of Environment and Natural Resources). (2006)

630 Basinwide assessment report Chowan River Basin. NCDENR. Raleigh, North Carolina.

631 NCDMF (North Carolina Division of Marine Fisheries). (2007) North Carolina fisheries management plan amendment 1 river herring. NCDMF. Morehead City, North Carolina. Newton, G.M. (1996) Estuarine ichthyoplankton ecology in relation to hydrology and zooplankton dynamics in a salt-wedge estuary. Marine and Freshwater Research. 47: 99-111.

635 Odum, E.P. (1980) The status of three ecosystem-level hypotheses regarding salt marsh estuaries: tidal subsidy, outwelling, and detritus-based food chains. In: Kennedy VS (ed) Estuarine Perspectives. Academic, New York. Orsi, J.J. and W.L. Mecum. (1986) Zooplankton distribution and abundance in the SacramentoSan Joaquin delta in relation to environmental factors. Estuaries 9, 326-339.

640 Park, G.S., and H.G. Marshall. (2000) The trophic contributions of rotifers in tidal freshwater and estuarine habitats. Estuarine, Coastal, and Shelf Science 51: 729-742.

642 Paulsen, M., C. Hammer, A.M. Malzahn, P. Polte, C. von Dorrien, and C. Clemmesen. (2014) Nutritional situation for larval Atlantic herring (Clupea harengus L.) in two nursery areas in the western Baltic Sea. ICES Journal of Marine Science 71: 991-1000.

644 Persson, J., and T. Verde. (2006) Polyunsaturated fatty acids in zooplankton: variation due to 645 taxonomy and trophic position. Freshwater Biology 51: 887-900. 
646 Rainuzzo, J.R., K.I. Reitan, and Y. Olsen. (1997) The significance of lipids at early stages of 647 marine fish: a review. Aquaculture 155: 103-115.

648 Ravet, J.L., M.T. Brett, and G.B. Arhonditsis. (2010) The effects of seston lipids on zooplankton

649 fatty acid composition in Lake Washington, Washington, USA. Ecology 9: 180-190.

650 Rossi, S., A. Sabates, M. Latasa and E. Reyes. (2006) Lipid biomarkers and trophic linkages

651 between phytoplankton, zooplankton and anchovy (Engraulis encrasicolus) larvae in the NW

652 Mediterranean. Journal of Plankton Research 28: 551-562.

653 RStudio Team (2015). RStudio: Integrated Development for R. RStudio, Inc., Boston, MA URL

654 http://www.rstudio.com/.

655 Rulifson, R.A., J.E. Cooper, D.W. Stanley, M.E. Shepherd, S.F. Wood and D.A. Daniel. (1993)

656 Food and feeding of young finfish species in lower Roanoke River, Batchelor Bay, and western

657 Albemarle Sound, North Carolina, 1982-1988. Albemarle-Pamlico Estuarine Study APES 90-

658 16:21-27 to U.S. Environmental Protection Agency.

659 Sargent, J., L. McEvoy, A. Estevez, G. Bell, M. Bell, J. Henderson, D. Tocher. (1999) Lipid

660 nutrition of marine fish during early development: current status and future directions.

661 Sheaves, M., R. Baker, I. Nagelkerken, and R.M. Connolly. (2015) True value of estuarine and

662 coastal nurseries for fish: incorporating complexity and dynamics. Estuaries Coast 38: 401-414.

663 Sheaves, M. (2016) Simple processes drive unpredictable differences in estuarine fish

664 assemblages: Baselines for understanding site specific ecological and anthropogenic impacts.

665 Estuarine, Coastal and Shelf Science 170: 61-69.

666 Smyntek, P.M., M.A. Teece, K.L. Schulz, and A.J. Storch. (2008) Taxonomic differences in the

667 essential fatty acid composition of groups of freshwater zooplankton relate to reproductive

668 demands and generation time. Freshwater Biology 53: 1768-1782.

669 Stottrup, J.G., J.G. Bell and J.R. Sargent. (1999) The fate of lipids during development and cold

670 storage of eggs in the laboratory-reared calanoid copepod, Acartia tonsa Dana, and in response

671 to different algal diets. Aquaculture 176: 257-269.

672 Tackx, M.L., N. de Pauw, R. van Mieghem, F. Azemar, A. Hannouti, S. van Damme, F. Fiers, N.

673 Daro, and P. Meire. (2004) Zooplankton in the Schelde estuary, Belgium and the Netherlands.

674 Spatial and temporal patterns. Journal of Plankton Research 26: 133-141.

675 Taipale, S., P. Kankaala, K. Hamalainen, R.I. Jones. (2008) Seasonal shifts in the diet of the lake

676 zooplankton revealed by phospholipid fatty acid analysis. Freshwater Biology 54: 90-104.

677 Townsend, D.W. 1983. The relations between larval fishes and zooplankton in two inshore areas

678 of the Gulf of Maine. Journal of Plankton Research 5: 145-173.

679 Vargas, C.A., R. Escribano, and S. Poulet. (2006) Phytoplankton food quality determines time

680 windows for successful zooplankton reproductive pulses. Ecology 87: 2992-2999.

681 Wacker, A. and E. von Elert. (2001) Polyunsaturated fatty acids: evidence for non-substitutable

682 biochemical resources in Daphnia galeata. Ecology 82: 2507-2520.

683 Walsh, H.J., L.R. Settle, and D.S. Peters. (2005) Early life history of blueback herring and

684 alewife in the lower Roanoke River, North Carolina. Transactions of the American Fisheries

685 Society 134: 910-926.

686 Winder, M. and A.D. Jassby. (2011) Shifts in zooplankton community structure: Implications for

687 food web processes in the upper San Francisco Estuary. Estuaries and Coasts 34: 675-690.

688 Webster, C.D. and R.T. Lovell. (1990) Response of striped bass larvae fed brine shrimp from

689 different sources containing different fatty acid compositions. Aquaculture 90: 49-61.

690 Webster, K.E. and R.H. Peters. (1978) Some size-dependent inhibitions of larger cladoceran

691 filterers in filamentous suspensions. Limnology and Oceanography 23: 1238-1245. 
692 Tables

693 Table 1: Results of SIMPER analysis for each group; all the zooplankton species that contributed 694 community composition, and their corresponding values in \% are given. Dash marks represent 695 species that were not included in the contribution of $70 \%$

\begin{tabular}{|l|cc|ccc|}
\hline & \multicolumn{2}{|c|}{ Microzooplankton } & \multicolumn{3}{c|}{ Mesozooplankton } \\
Group 1 & Group 2 & Group 3 & Group 4 & Group 5 \\
\hline Overall Similarity & $\mathbf{9 1 . 1 8}$ & $\mathbf{8 0 . 1 8}$ & $\mathbf{8 4 . 3 9}$ & $\mathbf{5 7 . 1 6}$ & $\mathbf{5 2 . 5 2}$ \\
\hline Species & \multicolumn{2}{|c|}{ Percent Composition } & \multicolumn{3}{|c|}{ Percent Composition } \\
\hline Bosminidae & - & - & 17.26 & 34.25 & 12.20 \\
Leptodora spp. & - & - & - & - & 21.80 \\
Calanoida & - & - & - & 33.32 & 26.09 \\
Cyclopoida & - & - & - & 10.24 & 9.07 \\
Acartia spp. & - & - & 74.66 & - & - \\
Copepod nauplii & 10.60 & 41.61 & - & - & - \\
Rotifer & 86.47 & 50.46 & - & - & - \\
\hline
\end{tabular}

696

697

698

699

700

701

702

703

704

705

706

707

708

709

710

711

712

713

714

715

716

717

718

719

720

721

722

723

724

725 
726 Table 2: Results of SIMPER analysis for each group; the fatty acids that contributed to the 727 differences in fatty acid profile, and their corresponding values in \% are given. Dash marks 728 represent fatty acids that were not included in the contribution of $70 \%$.

729 Group $\mathrm{G}$ had a sample size $<2$.

\begin{tabular}{|c|c|c|c|c|c|c|c|c|c|c|}
\hline & $\begin{array}{c}\text { Group } \\
\text { A }\end{array}$ & $\begin{array}{c}\text { Seston } \\
\text { Group } \\
\text { B }\end{array}$ & $\begin{array}{c}\text { Group } \\
\text { C }\end{array}$ & $\begin{array}{c}\text { Mic } \\
\text { Group } \\
\text { D }\end{array}$ & $\begin{array}{c}\text { Ozoopla } \\
\text { Group } \\
\text { E }\end{array}$ & $\begin{array}{l}\text { xton } \\
\text { Group } \\
\text { F }\end{array}$ & $\begin{array}{c}\text { Group } \\
\text { G }\end{array}$ & $\begin{array}{c}\text { Mesozod } \\
\text { Group } \\
\text { H }\end{array}$ & $\begin{array}{c}\text { olanktor } \\
\text { Group } \\
\text { I }\end{array}$ & $\begin{array}{c}\text { Group } \\
\mathbf{J}\end{array}$ \\
\hline $\begin{array}{l}\text { Overall } \\
\text { Similarity }\end{array}$ & 66.40 & 72.32 & 64.34 & 84.88 & 92.49 & 81.05 & N/A & 81.42 & 89.42 & 84.89 \\
\hline $\begin{array}{l}\text { Fatty } \\
\text { Acids }\end{array}$ & \multicolumn{3}{|c|}{ Percent Composition } & \multicolumn{3}{|c|}{ Percent Composition } & \multicolumn{4}{|c|}{ Percent Composition } \\
\hline $16: 1 \omega-7$ & 3.12 & 6.53 & - & - & - & 7.98 & - & 9.53 & - & 8.51 \\
\hline $18: 1 \omega-9$ & 7.04 & 2.27 & 2.42 & 31.63 & 13.46 & - & 17.01 & 10.58 & - & - \\
\hline $18: 2 \omega-6$ & - & - & - & 12.15 & - & - & - & - & - & - \\
\hline $\begin{array}{c}18: 3 \omega-3 \\
\text { (ALA) }\end{array}$ & 2.37 & - & 3.33 & - & 8.43 & 6.80 & - & 6.14 & 10.65 & - \\
\hline $18: 4 \omega-3$ & - & - & - & - & 10.29 & - & - & - & 7.05 & - \\
\hline $\begin{array}{c}20: 5 \omega-3 \\
\text { (EPA) }\end{array}$ & - & 1.55 & 2.44 & - & 11.72 & 9.91 & - & 11.24 & 13.84 & 16.40 \\
\hline $\begin{array}{c}22: 6 \omega-3 \\
\text { (DHA) }\end{array}$ & - & - & 1.87 & - & - & 9.45 & - & - & 10.11 & 16.58 \\
\hline
\end{tabular}

755 Figures 


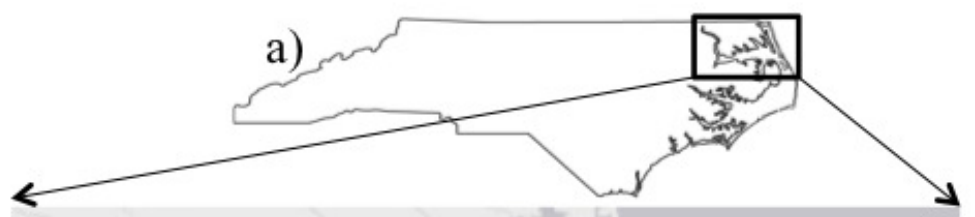

b)

c)
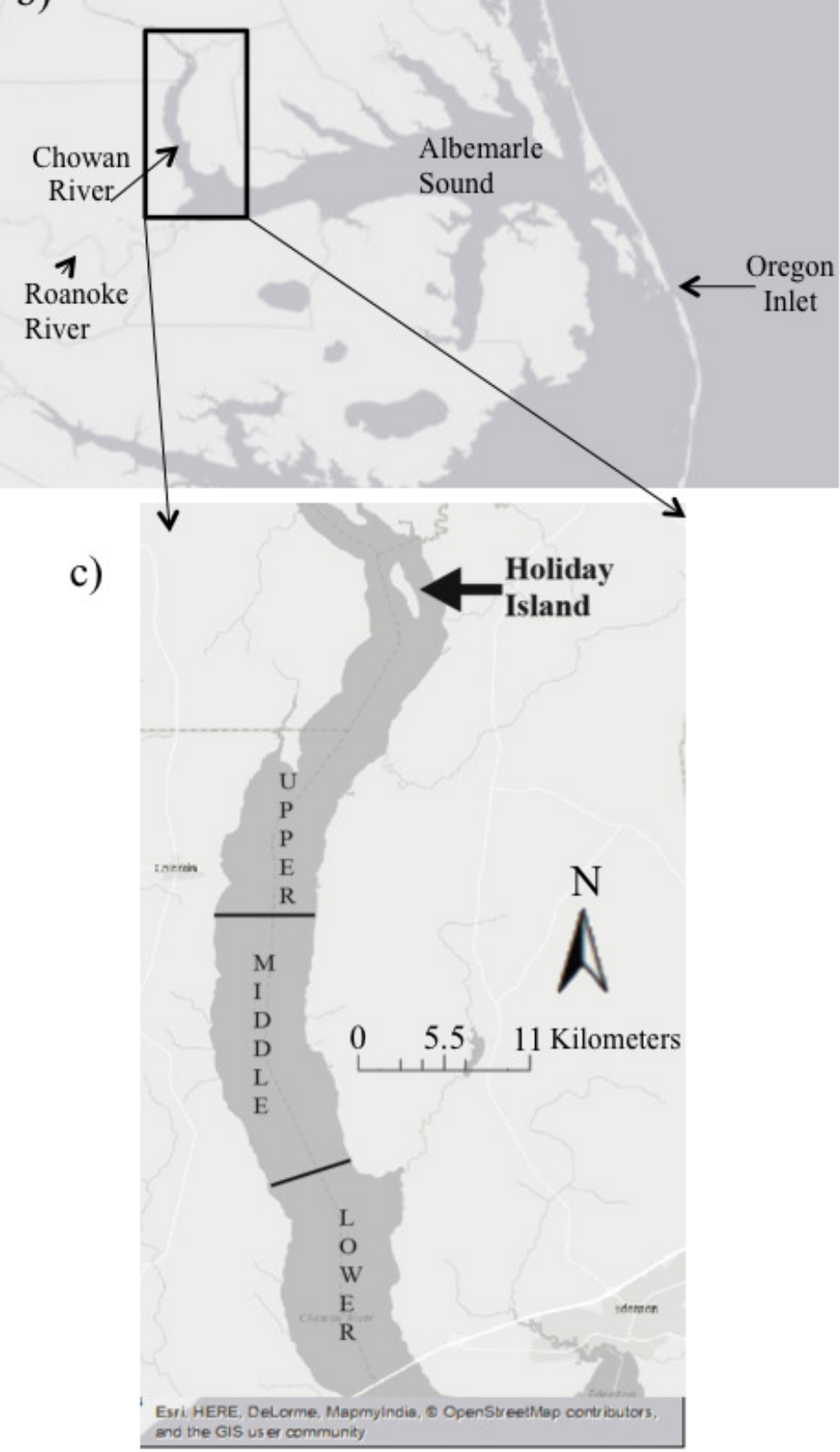

Figure 1. The overview of Albemarle Sound in North Carolina (a). The close up view of the 758 location for two main tributaries (Chowan and Roanoke Rivers), and the Albemarle Sound in 759 North Carolina (b). The three sections used to collect zooplankton on the Chowan River (c). 
a)

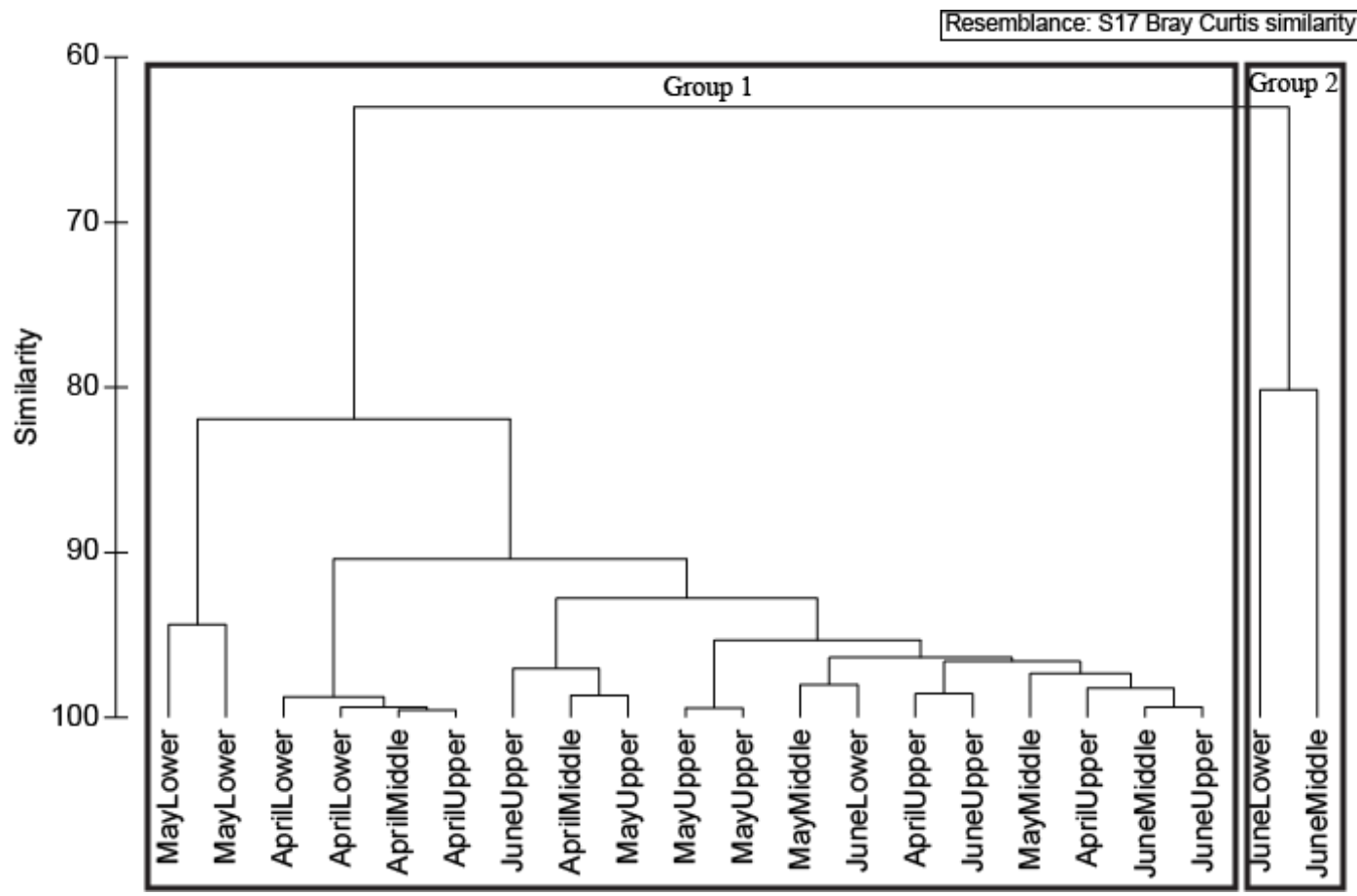

b)

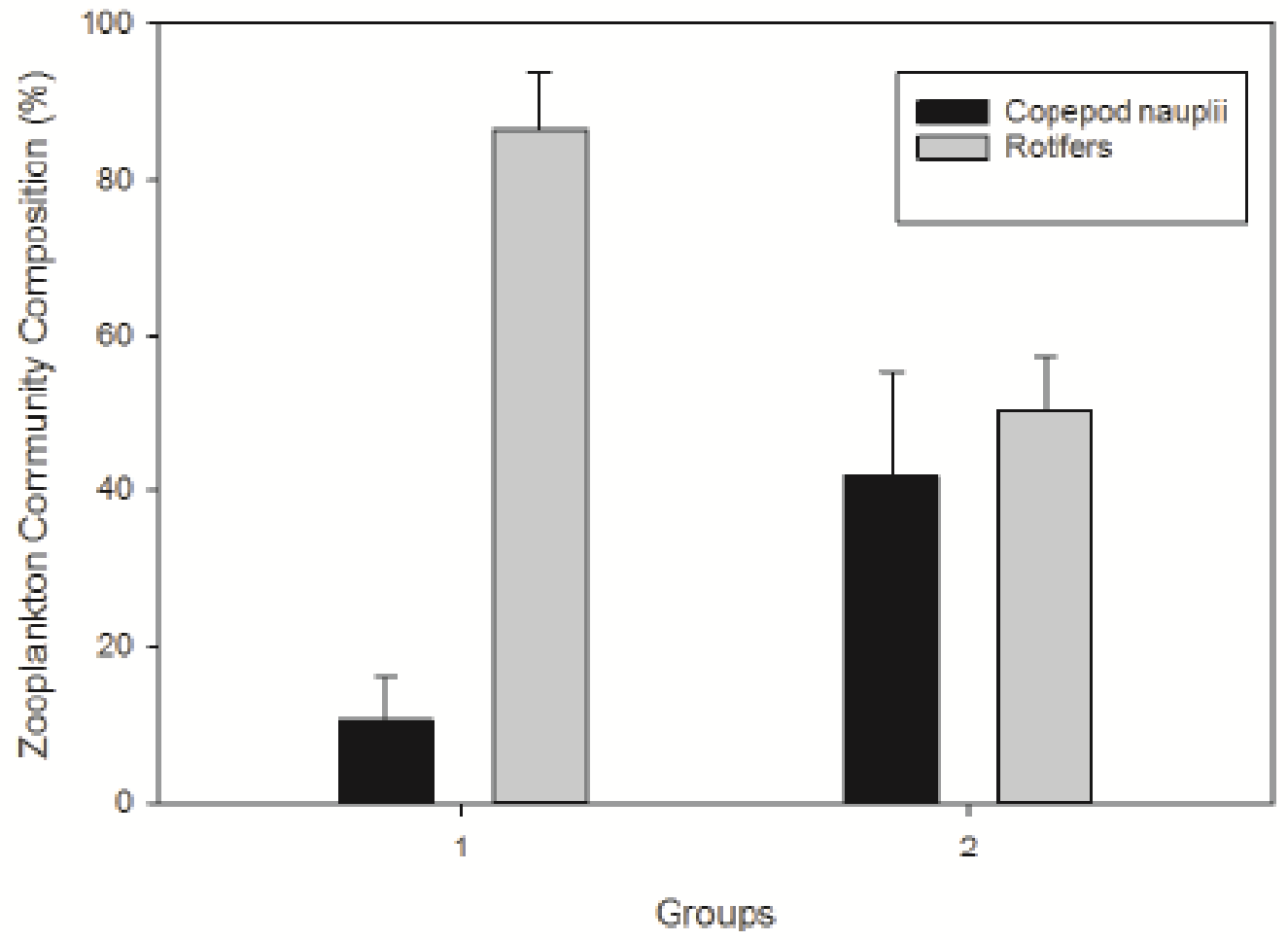

762

763

764

765
Figure 2. The two microzooplankton community composition groups from cluster analysis (a) at $65 \%$ similarity. The mean microzooplankton community composition $(\%, \pm$ S.D. $)$ for the two groups from cluster analysis (b). 
a)

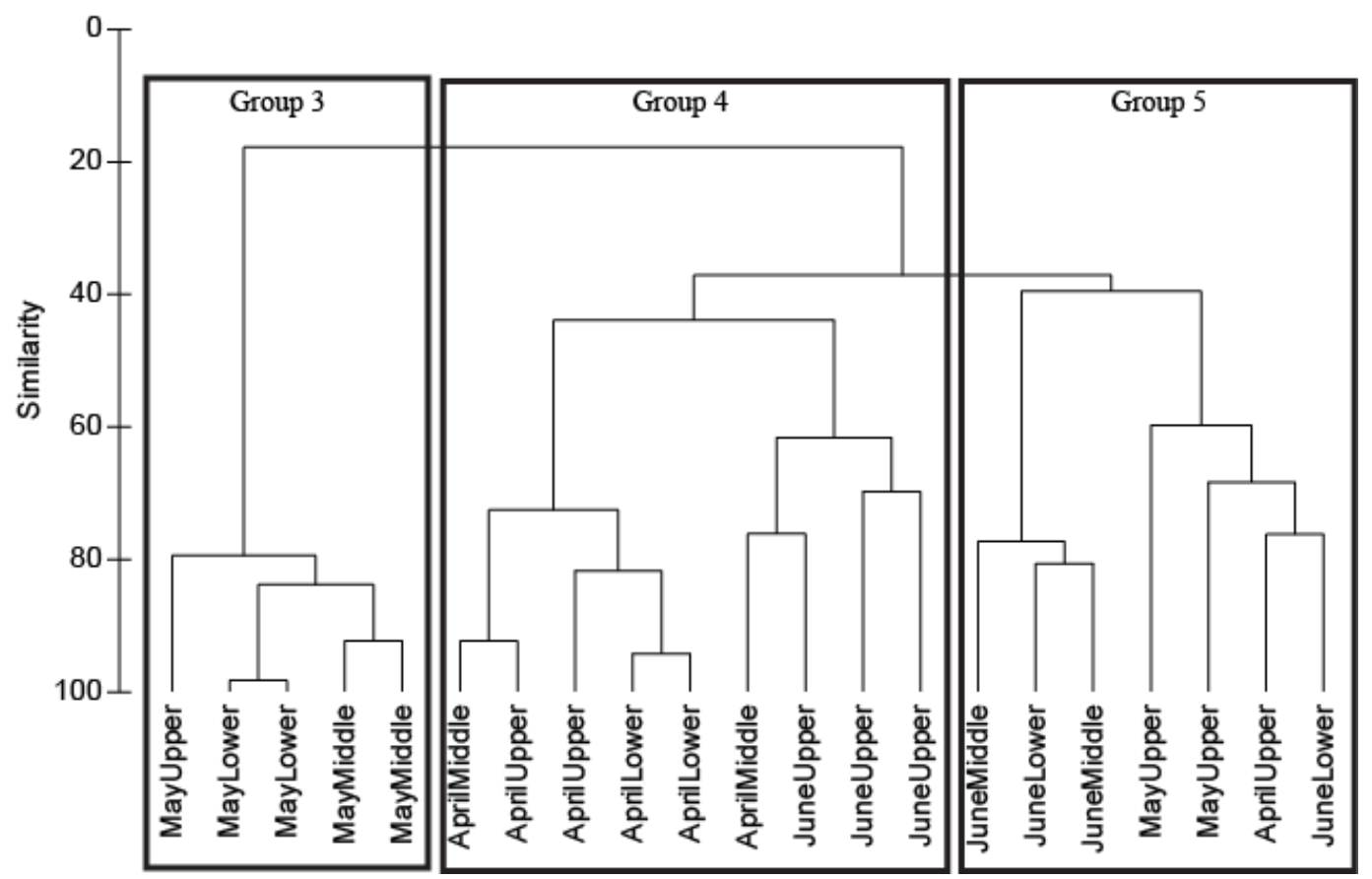

767

768

b)

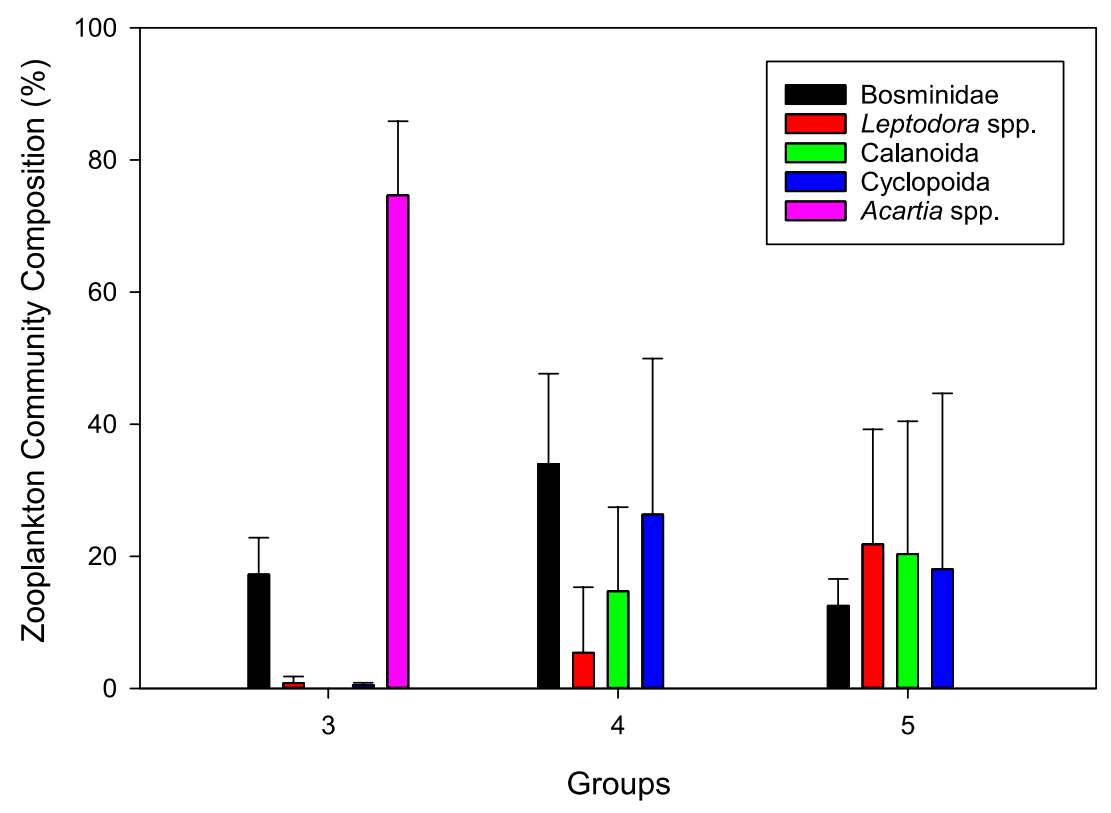

Figure 3. The three mesozooplankton community composition groups from cluster analysis (a) at

$77150 \%$ similarity. The mean mesozooplankton community composition ( $\%, \pm$ S.D.) for the three

772 groups from cluster analysis (b). 

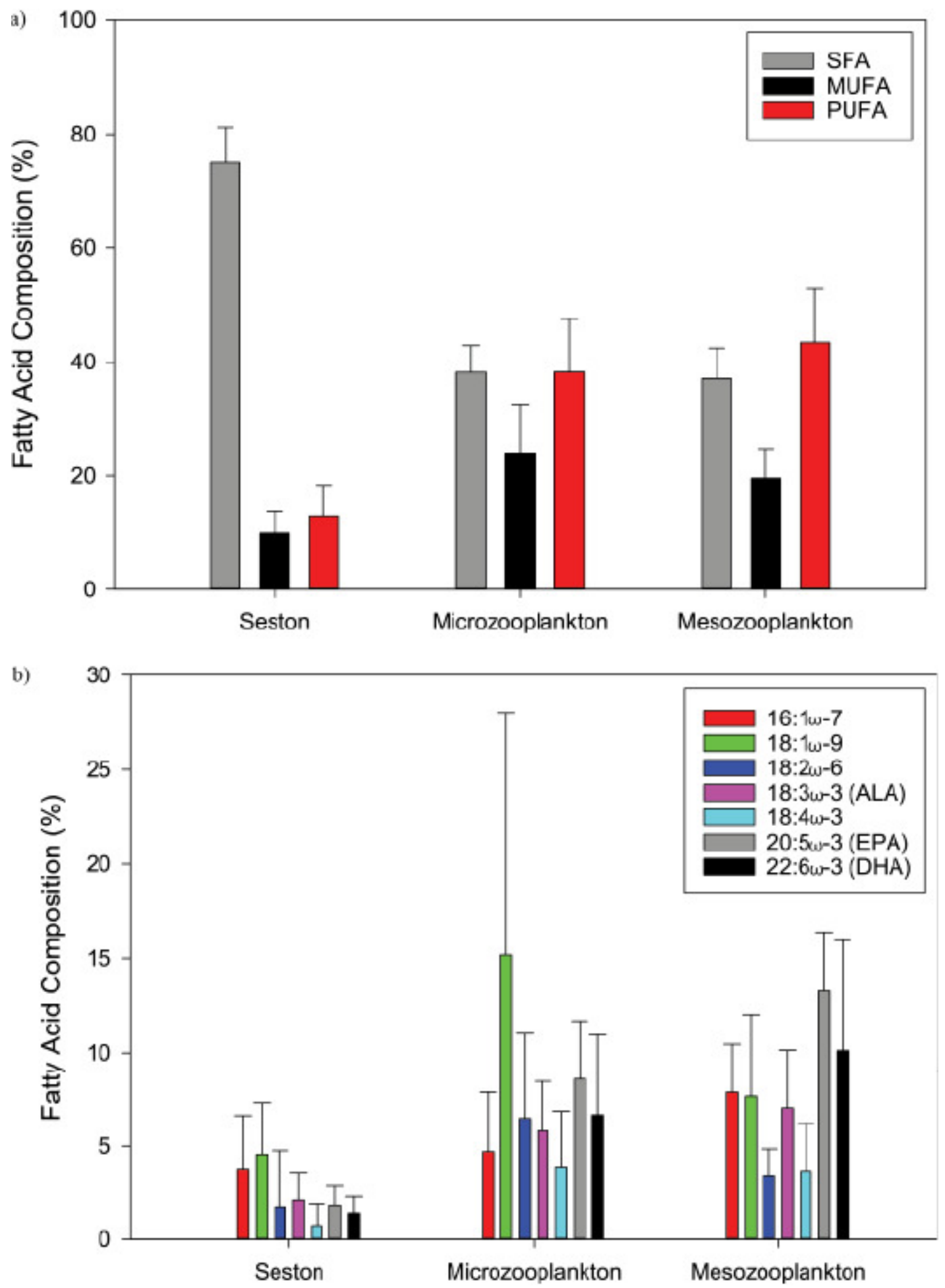

Figure 4. The mean ( \pm S.D.) saturated (SFA), monounsaturated (MUFA), and polyunsaturated (PUFA) fatty acid composition (\%) for the seston, microzooplankton, and mesozooplankton (a).

778 The mean fatty acid composition $(\%, \pm$ S.D.) for the seston, microzooplankton, and 779 mesozooplankton (b). 
Resemblance: S17 Bray Curtis simlliarty

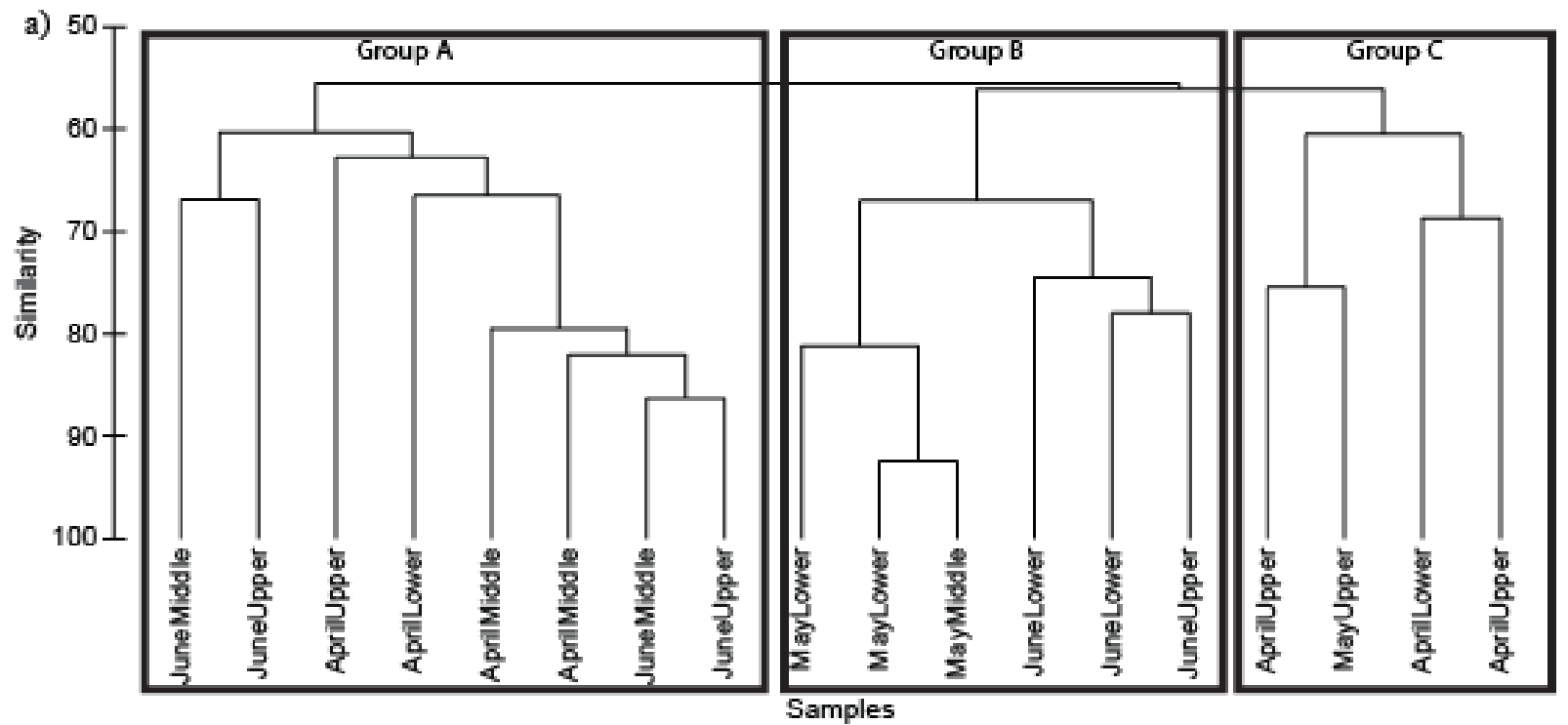

b)

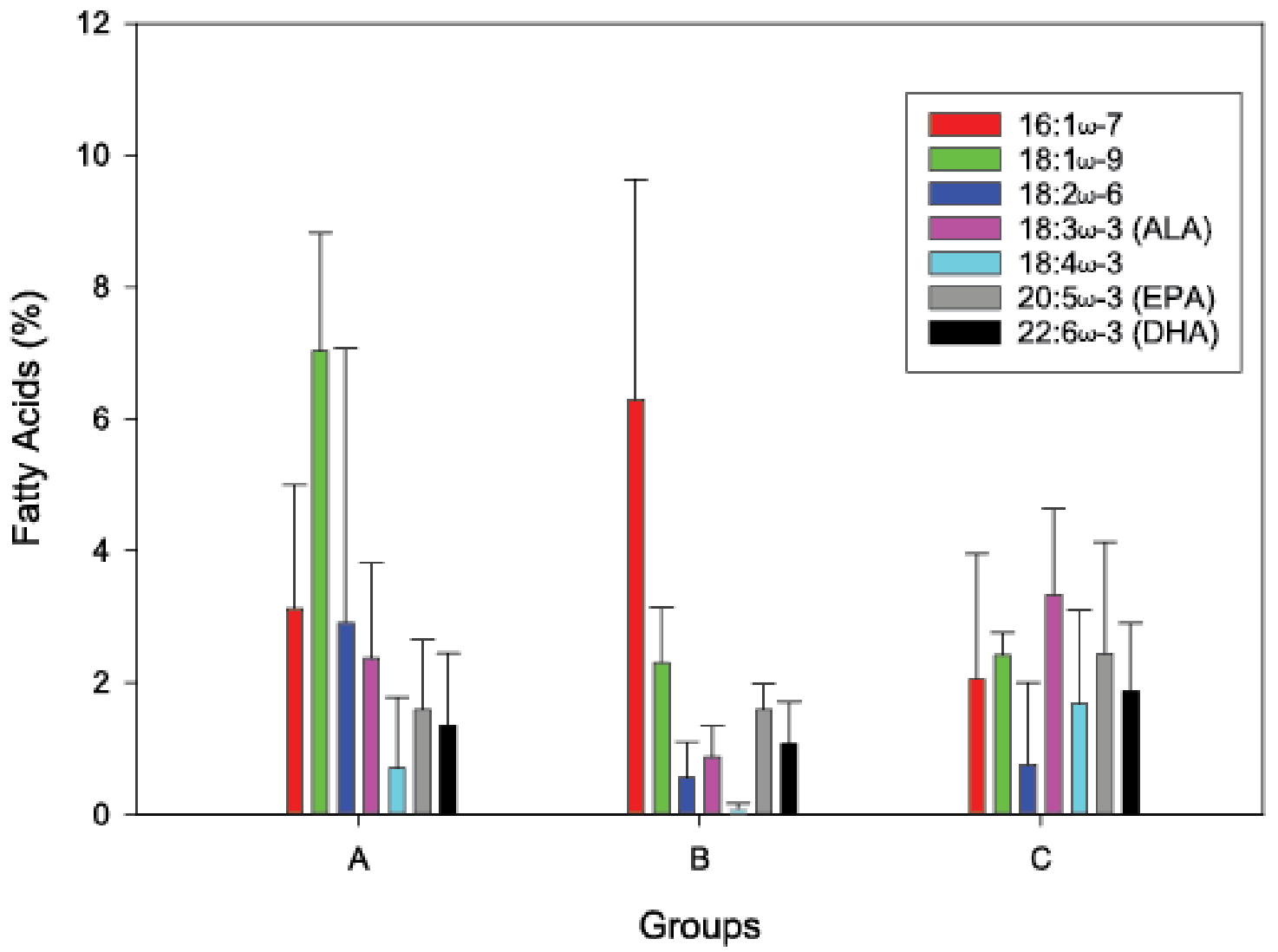

Figure 5. The three seston fatty acid composition groups from cluster analysis (a) at $60 \%$ analysis (b). 


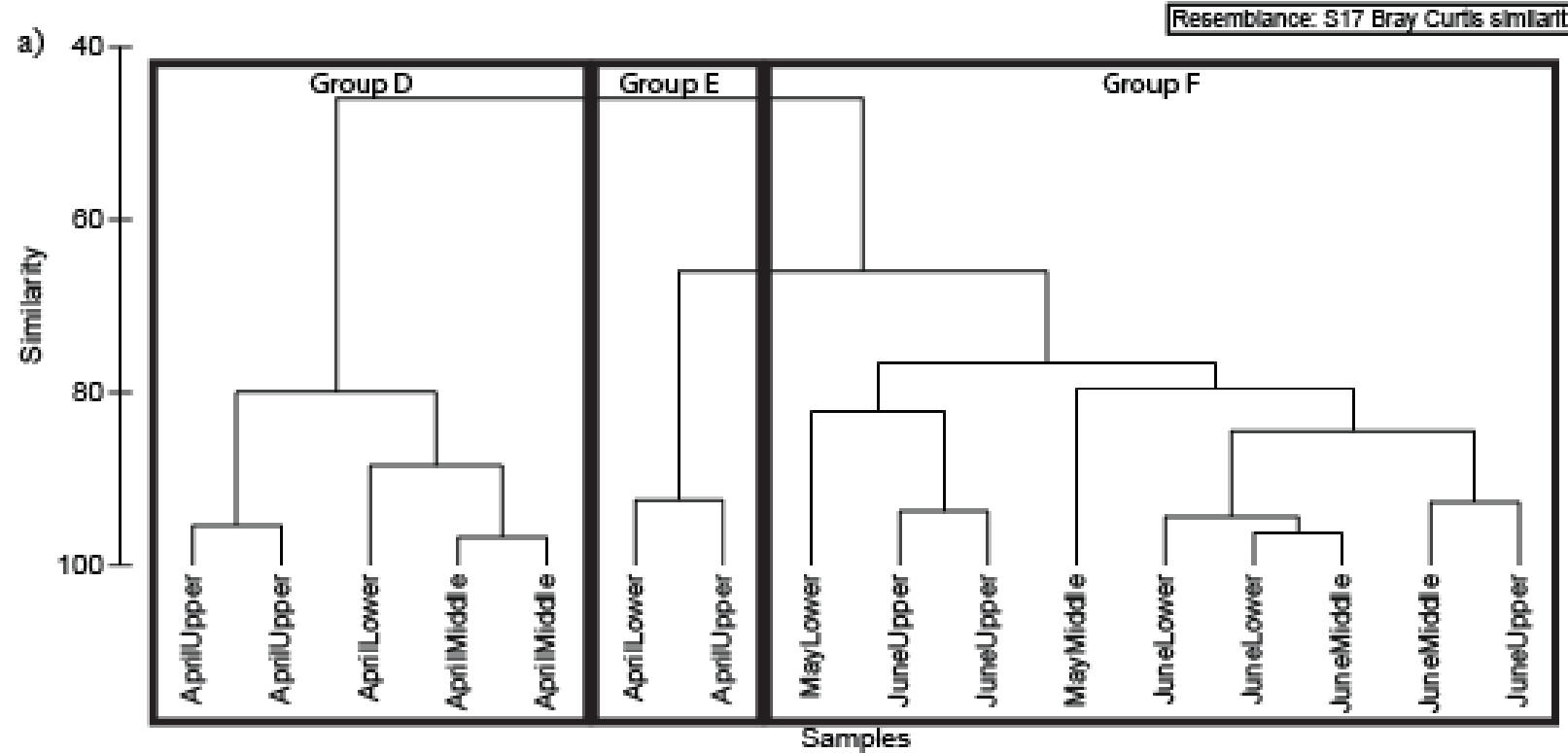

b)

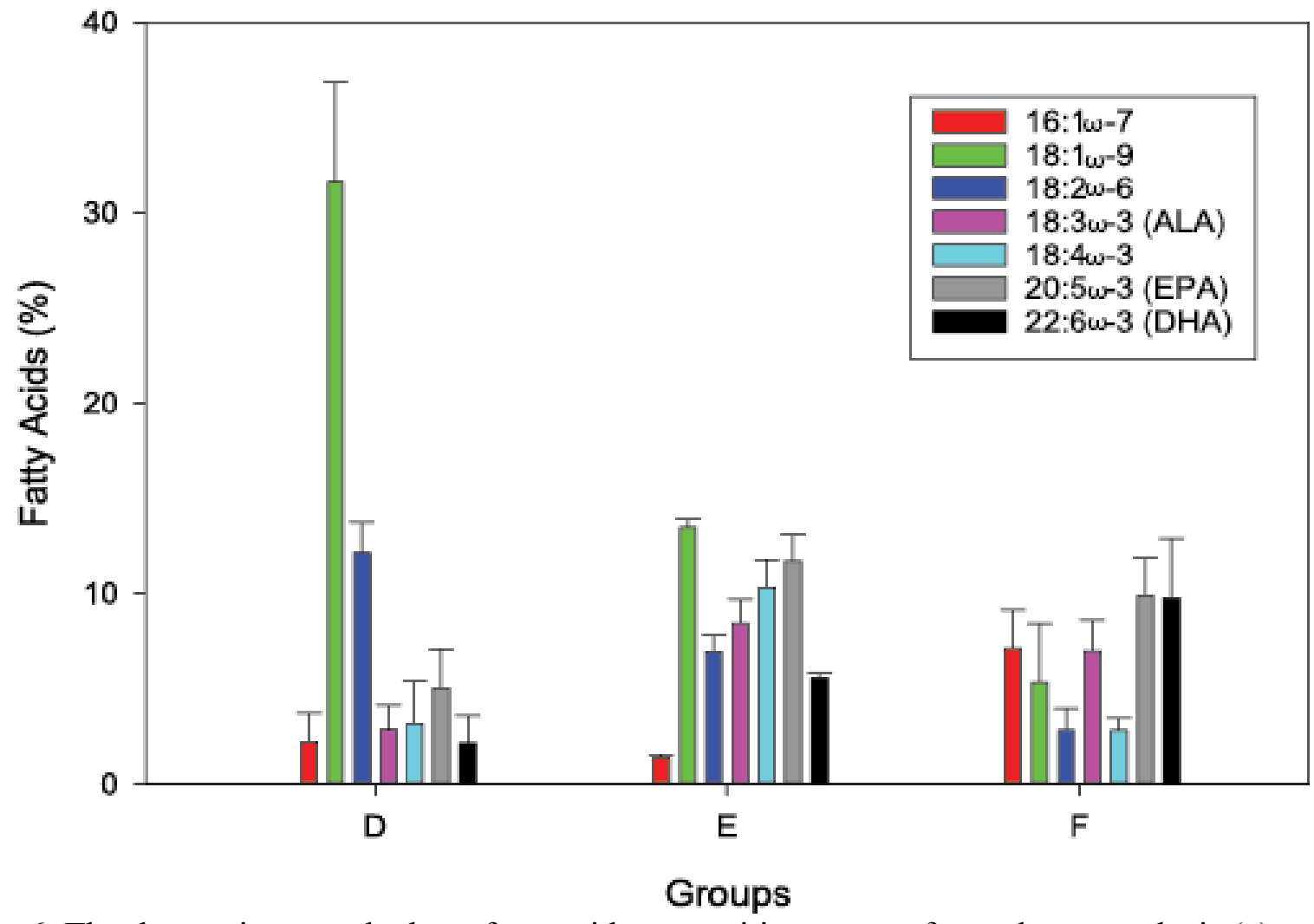

Figure 6. The three microzooplankton fatty acid composition groups from cluster analysis (a) at 787 $60 \%$ similarity. The mean microzooplankton fatty acid composition $(\%, \pm$ S.D. $)$ for the three groups from cluster analysis (b). 

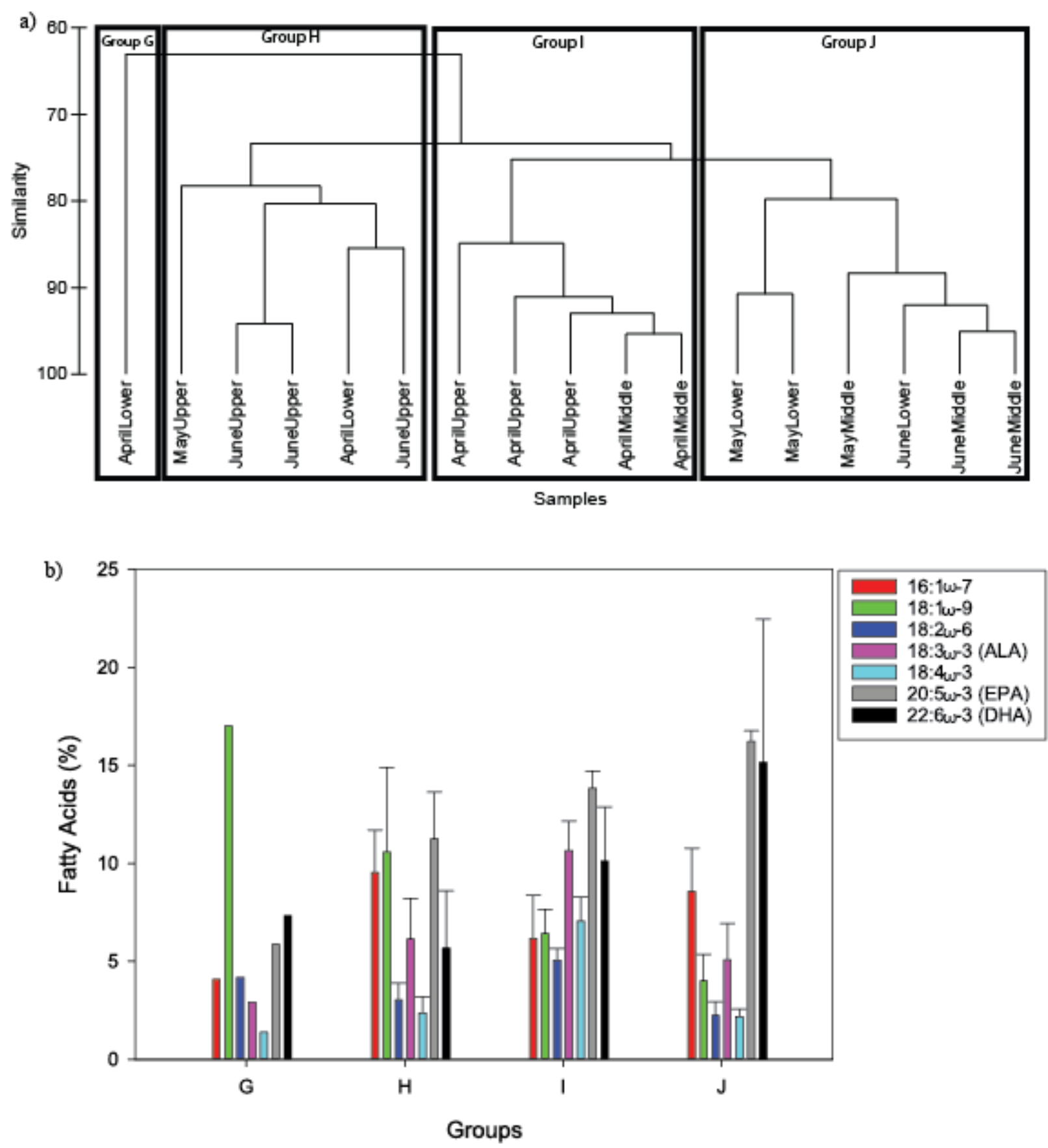

Figure 7. The four mesozooplankton fatty acid composition groups from cluster analysis (a) at $60 \%$ similarity. The mean mesozooplankton fatty acid composition $(\%, \pm$ S.D. $)$ for the four groups from cluster analysis (b). 


\section{Appendix}

800

Table A1: Mean fatty acid composition ( \pm standard deviation) (percentage of total fatty acids

801 detected) of seston from the Chowan River by group. SFA: saturated fatty acids, MUFA:

802 monounsaturated fatty acids, and PUFA: polyunsaturated fatty acids.

\begin{tabular}{|cccc|}
\cline { 2 - 4 } \multicolumn{1}{c|}{} & \multicolumn{3}{c|}{$\begin{array}{c}\text { Seston } \\
\text { Group }\end{array}$} \\
\cline { 2 - 4 } & $\mathbf{A ~ ( 8 )}$ & $\mathbf{B ~ ( 5 )}$ & $\mathbf{C ~ ( 4 )}$ \\
\hline $14: 0$ & $6.6 \pm 1.8$ & $11.2 \pm 5.1$ & $7.6 \pm 1.0$ \\
$15: 0$ & $1.5 \pm 1.5$ & $1.3 \pm 0.4$ & $1.7 \pm 0.3$ \\
$16: 0$ & $47.7 \pm 5.5$ & $54.0 \pm 5.1$ & $50.8 \pm 4.4$ \\
$17: 0$ & $2.3 \pm 0.4$ & $2.7 \pm 0.7$ & $2.6 \pm 0.2$ \\
$18: 0$ & $14.2 \pm 5.6$ & $9.7 \pm 1.2$ & $11.4 \pm 2.5$ \\
$20: 0$ & $0.4 \pm 0.3$ & $0.3 \pm 0.1$ & $0.4 \pm 0.2$ \\
$\sum$ SFA & $\mathbf{7 2 . 7}$ & $\mathbf{7 9 . 2}$ & $\mathbf{7 4 . 0}$ \\
$16: 1 \omega-9$ & $1.2 \pm 1.0$ & $1.3 \pm 0.6$ & $1.6 \pm 0.7$ \\
$16: 1 \omega-7$ & $3.1 \pm 1.9$ & $6.3 \pm 3.3$ & $2.1 \pm 1.9$ \\
$18: 1 \omega-9$ & $7.0 \pm 1.8$ & $2.3 \pm 0.8$ & $2.4 \pm 0.3$ \\
$18: 1 \omega-7$ & $0.3 \pm 0.2$ & $0.1 \pm 0.2$ & $0.1 \pm 0.1$ \\
$20: 1$ & $0.1 \pm 0.0$ & $0.1 \pm 0.0$ & $0.2 \pm 0.1$ \\
$\sum$ MUFA & $\mathbf{1 1 . 7}$ & $\mathbf{1 0 . 1}$ & $\mathbf{6 . 4}$ \\
$18: 2 \omega-6$ & $2.9 \pm 4.2$ & $0.6 \pm 0.6$ & $0.8 \pm 1.2$ \\
$18: 3 \omega-3$ & $2.4 \pm 1.4$ & $0.9 \pm 0.5$ & $3.3 \pm 1.3$ \\
$18: 4 \omega-3$ & $0.7 \pm 1.1$ & $0.1 \pm 0.1$ & $1.7 \pm 1.4$ \\
$20: 2 \omega-6$ & $0.5 \pm 0.4$ & $0.2 \pm 0.2$ & $0.7 \pm 0.5$ \\
$20: 3 \omega-6$ & $0.4 \pm 0.1$ & $0.4 \pm 0.3$ & $0.3 \pm 0.2$ \\
$20: 4 \omega-6$ & $0.9 \pm 0.6$ & $0.8 \pm 0.4$ & $0.8 \pm 0.5$ \\
$20: 3 \omega-3$ & $0.6 \pm 0.3$ & $0.4 \pm 0.3$ & $1.1 \pm 0.6$ \\
$20: 4 \omega-3$ & $0.6 \pm 1.4$ & $0.5 \pm 0.3$ & $2.3 \pm 1.9$ \\
$20: 5 \omega-3$ & $1.6 \pm 1.1$ & $1.6 \pm 0.4$ & $2.4 \pm 1.7$ \\
$22: 5 \omega-6$ & $0.7 \pm 0.5$ & $0.8 \pm 0.8$ & $1.2 \pm 0.6$ \\
$22: 5 \omega-3$ & $0.8 \pm 0.6$ & $0.7 \pm 0.6$ & $1.2 \pm 0.7$ \\
$22: 6 \omega-3$ & $1.4 \pm 1.1$ & $1.1 \pm 0.6$ & $1.9 \pm 1.0$ \\
$\sum$ PUFA & $\mathbf{1 3 . 5}$ & $\mathbf{8 . 1}$ & $\mathbf{1 7 . 7}$ \\
\hline
\end{tabular}


814 Table A2: Mean fatty acid composition (percentage of total fatty acids detected) of 815 microzooplankton $(<60 \mu \mathrm{m})$ from the Chowan River by groups. SFA: saturated fatty acids, 816 MUFA: monounsaturated fatty acids, and PUFA: polyunsaturated fatty acids.

\begin{tabular}{|c|c|c|c|}
\hline & \multicolumn{3}{|c|}{$\begin{array}{c}\text { Microzooplankton } \\
\text { Groups } \\
\end{array}$} \\
\hline & D (5) & E (2) & F (8) \\
\hline $14: 0$ & $2.6 \pm 0.5$ & $3.7 \pm 0.9$ & $5.9 \pm 1.1$ \\
\hline $15: 0$ & $0.3 \pm 0.1$ & $0.5 \pm 0.2$ & $1.1 \pm 0.3$ \\
\hline $16: 0$ & $27.4 \pm 3.0$ & $24.5 \pm 0.3$ & $23.5 \pm 3.4$ \\
\hline $17: 0$ & $0.4 \pm 0.1$ & $0.6 \pm 0.0$ & $1.2 \pm 0.3$ \\
\hline 18:0 & $3.4 \pm 0.8$ & $3.4 \pm 0.0$ & $7.1 \pm 0.3$ \\
\hline $20: 0$ & $1.8 \pm 0.4$ & $0.8 \pm 0.1$ & $0.2 \pm 0.1$ \\
\hline$\sum$ SFA & 35.9 & 33.5 & 39.0 \\
\hline $16: 1 \omega-9$ & $0.3 \pm 0.1$ & $0.8 \pm 0.3$ & $0.9 \pm 0.6$ \\
\hline $16: 1 \omega-7$ & $2.2 \pm 1.6$ & $1.4 \pm 0.1$ & $7.1 \pm 2.0$ \\
\hline $18: 1 \omega-9$ & $31.6 \pm 5.3$ & $13.5 \pm 0.5$ & $5.3 \pm 3.1$ \\
\hline $18: 1 \omega-7$ & $0.7 \pm 0.8$ & $0.8 \pm 0.2$ & $1.9 \pm 0.5$ \\
\hline 20:1 & $0.6 \pm 0.2$ & $0.8 \pm 0.1$ & $1.4 \pm 0.6$ \\
\hline$\sum$ MUFA & 35.4 & 17.3 & 16.6 \\
\hline $18: 2 \omega-6$ & $12.2 \pm 1.6$ & $6.9 \pm 0.9$ & $2.8 \pm 1.2$ \\
\hline $18: 3 \omega-3$ & $2.9 \pm 1.3$ & $8.4 \pm 1.3$ & $7.0 \pm 1.7$ \\
\hline $18: 4 \omega-3$ & $3.2 \pm 2.3$ & $10.3 \pm 1.5$ & $2.8 \pm 0.7$ \\
\hline $20: 2 \omega-6$ & $0.4 \pm 0.1$ & $0.5 \pm 0.1$ & $0.3 \pm 0.1$ \\
\hline $20: 3 \omega-6$ & $0.1 \pm 0.1$ & $0.1 \pm 0.0$ & $0.2 \pm 0.1$ \\
\hline $20: 4 \omega-6$ & $0.6 \pm 0.7$ & $0.4 \pm 0.1$ & $3.2 \pm 0.5$ \\
\hline $20: 3 \omega-3$ & $0.3 \pm 0.1$ & $1.0 \pm 0.2$ & $0.4 \pm 0.1$ \\
\hline $20: 4 \omega-3$ & $1.3 \pm 0.4$ & $2.8 \pm 0.1$ & $2.1 \pm 0.3$ \\
\hline $20: 5 \omega-3$ & $5.0 \pm 2.0$ & $11.7 \pm 1.4$ & $9.9 \pm 2.0$ \\
\hline $22: 5 \omega-6$ & $0.2 \pm 0.2$ & $1.0 \pm 0.1$ & $2.3 \pm 0.9$ \\
\hline $22: 5 \omega-3$ & $0.2 \pm 0.2$ & $0.2 \pm 0.1$ & $1.9 \pm 1.1$ \\
\hline $22: 6 \omega-3$ & $2.1 \pm 1.5$ & $5.6 \pm 0.3$ & $9.8 \pm 3.2$ \\
\hline$\sum$ PUFA & 28.5 & 48.9 & 42.7 \\
\hline
\end{tabular}


830 a: Mean fatty acid composition ( \pm standard deviation) (percentage of total fatty acids detected) of 831 mesozooplankton from the Chowan River by group. SFA: saturated fatty acids, MUFA:

832 monounsaturated fatty acids, and PUFA: polyunsaturated fatty acids.

\begin{tabular}{|ccccc|}
\cline { 2 - 5 } & \multicolumn{4}{c|}{$\begin{array}{c}\text { Mesozooplankton } \\
\text { Groups }\end{array}$} \\
\cline { 2 - 5 } & $\mathbf{G ~ ( 1 )}$ & $\mathbf{H ~ ( 5 )}$ & $\mathbf{I} \mathbf{( 5 )}$ & $\mathbf{J}(\mathbf{5 )}$ \\
\hline $14: 0$ & 4.5 & $5.4 \pm 0.9$ & $5.2 \pm 1.1$ & $5.1 \pm 1.1$ \\
$15: 0$ & 1.1 & $1.1 \pm 0.4$ & $0.7 \pm 0.0$ & $0.9 \pm 0.1$ \\
$16: 0$ & 29.7 & $24.4 \pm 2.6$ & $19.5 \pm 1.3$ & $22.0 \pm 1.5$ \\
$17: 0$ & 1.3 & $1.4 \pm 0.4$ & $1.0 \pm 0.1$ & $1.4 \pm 0.3$ \\
$18: 0$ & 11.2 & $7.7 \pm 1.2$ & $5.1 \pm 0.3$ & $6.8 \pm 0.7$ \\
$20: 0$ & 0.4 & $0.2 \pm 0.0$ & $0.2 \pm 0.1$ & $0.1 \pm 0.1$ \\
$\sum$ SFA & $\mathbf{4 8 . 2}$ & $\mathbf{4 0 . 2}$ & $\mathbf{3 1 . 7}$ & $\mathbf{3 6 . 3}$ \\
$16: 1 \omega-9$ & 0.3 & $0.9 \pm 0.2$ & $0.9 \pm 0.4$ & $0.8 \pm 0.4$ \\
$16: 1 \omega-7$ & 4.1 & $9.5 \pm 2.2$ & $6.2 \pm 2.2$ & $8.6 \pm 2.2$ \\
$18: 1 \omega-9$ & 17.0 & $10.6 \pm 4.3$ & $6.4 \pm 1.2$ & $4.0 \pm 1.4$ \\
$18: 1 \omega-7$ & 2.1 & $3.9 \pm 1.7$ & $2.4 \pm 0.4$ & $3.0 \pm 1.1$ \\
$20: 1$ & 0.3 & $0.1 \pm 0.1$ & $0.3 \pm 0.1$ & $0.2 \pm 0.1$ \\
$\sum$ MUFA & $\mathbf{2 3 . 8}$ & $\mathbf{2 5 . 0}$ & $\mathbf{1 6 . 2}$ & $\mathbf{1 6 . 6}$ \\
$18: 2 \omega-6$ & 4.2 & $3.0 \pm 0.9$ & $5.1 \pm 0.6$ & $2.2 \pm 0.7$ \\
$18: 3 \omega-3$ & 2.9 & $6.1 \pm 2.1$ & $10.7 \pm 1.5$ & $5.1 \pm 1.9$ \\
$18: 4 \omega-3$ & 1.4 & $2.4 \pm 0.8$ & $7.1 \pm 1.2$ & $2.2 \pm 0.4$ \\
$20: 2 \omega-6$ & 0.2 & $0.2 \pm 0.1$ & $0.4 \pm 0.1$ & $0.2 \pm 0.0$ \\
$20: 3 \omega-6$ & 0.1 & $0.1 \pm 0.0$ & $0.1 \pm 0.0$ & $0.1 \pm 0.0$ \\
$20: 4 \omega-6$ & 3.7 & $4.2 \pm 1.5$ & $2.1 \pm 0.6$ & $2.5 \pm 1.2$ \\
$20: 3 \omega-3$ & 0.2 & $0.2 \pm 0.1$ & $0.5 \pm 0.3$ & $0.2 \pm 0.1$ \\
$20: 4 \omega-3$ & 0.8 & $0.6 \pm 0.3$ & $1.2 \pm 0.6$ & $0.8 \pm 0.3$ \\
$20: 5 \omega-3$ & 5.9 & $11.2 \pm 2.4$ & $13.8 \pm 0.9$ & $16.2 \pm 0.6$ \\
$22: 5 \omega-6$ & 0.4 & $0.4 \pm 0.2$ & $0.8 \pm 0.2$ & $1.8 \pm 0.8$ \\
$22: 5 \omega-3$ & 0.4 & $0.3 \pm 0.2$ & $0.4 \pm 0.2$ & $0.6 \pm 0.3$ \\
$22: 6 \omega-3$ & 7.3 & $5.7 \pm 2.9$ & $10.1 \pm 2.8$ & $15.1 \pm 7.3$ \\
$\sum$ PUFA & $\mathbf{2 7 . 5}$ & $\mathbf{3 4 . 4}$ & $\mathbf{5 2 . 3}$ & $\mathbf{4 7 . 0}$ \\
\hline
\end{tabular}

